\title{
On the occurrence and motion of decametre-scale irregularities in the sub-auroral, auroral, and polar cap ionosphere
}

\author{
M. L. Parkinson ${ }^{1}$, J. C. Devlin ${ }^{2}$, H. Ye ${ }^{2}$, C. L. Waters ${ }^{3}$, P. L. Dyson ${ }^{1}$, A. M. Breed ${ }^{4, *}$, and R. J. Morris ${ }^{4}$ \\ ${ }^{1}$ Department of Physics, La Trobe University, Victoria 3086, Australia \\ ${ }^{2}$ Department of Electronic Engineering, La Trobe University, Victoria 3086, Australia \\ ${ }^{3}$ Department of Physics, University of Newcastle, New South Wales 2038, Australia \\ ${ }^{4}$ Atmospheric and Space Physics, Australian Antarctic Division, Kingston, Tasmania 7050, Australia \\ *Deceased 5 September 2002
}

Received: 5 November 2002 - Revised: 11 March 2003 - Accepted: 25 March 2003

\begin{abstract}
The statistical occurrence of decametrescale ionospheric irregularities, average line-of-sight (LOS) Doppler velocity, and Doppler spectral width in the subauroral, auroral, and polar cap ionosphere $\left(-57^{\circ} \Lambda\right.$ to $-88^{\circ} \Lambda$ ) has been investigated using echoes recorded with the Tasman International Geospace Environment Radar (TIGER), a SuperDARN radar located on Bruny Island, Tasmania $\left(147.2^{\circ} \mathrm{E}, 43.4^{\circ} \mathrm{S}\right.$ geographic; $\left.-54.6^{\circ} \Lambda\right)$. Results are shown for routine soundings made on the magnetic meridian beam 4 and the near zonal beam 15 during the sunspot maximum interval December 1999 to November 2000. Most echoes were observed in the nightside ionosphere, typically via 1.5 -hop propagation near dusk and then via 0.5 -hop propagation during pre-midnight to dawn. Peak occurrence rates on beam 4 were often $>60 \%$ near magnetic midnight and $\sim-70^{\circ} \Lambda$. They increased and shifted equatorward and toward pre-midnight with increasing $K_{p}$ (i.e. $B_{z}$ southward). The occurrence rates remained very high for $K_{p}>4$, despite enhanced D-region absorption due to particle precipitation. Average occurrence rates on beam 4 exhibited a relatively weak seasonal variation, consistent with known longitudinal variations in auroral zone magnetic activity (Basu, 1975). The average echo power was greatest between 23 and 07 MLT. Two populations of echoes were identified on both beams, those with low spectral width and a mode value of $\sim 9 \mathrm{~m} \mathrm{~s}^{-1}$ (bin size of $2 \mathrm{~m} \mathrm{~s}^{-1}$ ) concentrated in the auroral and sub-auroral ionosphere (population A), and those with high spectral width and a mode value of $\sim 70 \mathrm{~m} \mathrm{~s}^{-1}$ concentrated in the polar cap ionosphere (population B). The occurrence of population A echoes maximised post-midnight because of TIGER's lower latitude, but the subset of the population A echoes observed near dusk had characteristics reminiscent of "dusk scatter" (Ruohoniemi et al., 1988). There was a dusk "bite out" of large spectral widths between $\sim 15$ and 21 MLT and poleward of $-67^{\circ} \Lambda$, and a predawn enhancement of large spectral widths between $\sim 03$ and
\end{abstract}

Correspondence to: M. L. Parkinson

(m.parkinson@latrobe.edu.au)
07 MLT, centred on $\sim-61^{\circ} \Lambda$. The average LOS Doppler velocities revealed that frequent westward jets of plasma flow occurred equatorward of, but overlapping, the diffuse auroral oval in the pre-midnight sector.

Key words. Ionosphere (auroral ionosphere; electric fields and currents, ionospheric irregularities)

\section{Introduction}

It is well known that the transfer of solar-wind energy and momentum to the coupled magnetosphere-ionospherethermosphere system is constantly changing due to fluctuations in magnetic reconnection, turbulent boundary layer processes, and dynamic pressure in the solar wind (Kivelson and Russell, 1995). Variations in ionospheric conductivity and thermospheric winds also regulate the flow of energy throughout the system. Some authors have found evidence suggesting these processes, including the magnetospheric boundaries formed by them, produce reasonably distinct signatures in the motion of ionospheric irregularities (e.g. Lester et al., 2001; Pinnock et al., 1993). However, there are still outstanding issues, such as identifying the best theoretical description of magnetospheric substorms (Lui, 2001), a phenomenon that is well known to produce brilliant auroral displays and dramatic changes in the distribution of ionospheric irregularities (e.g. Lewis et al., 1997; Yeoman et al., 1999).

The Super Dual Auroral Radar Network (SuperDARN) is a ground-based network of high frequency (HF) backscatter radars providing global scale coverage of the occurrence, amplitude, and motion of decametre-scale ionospheric irregularities in response to dynamic high-latitude processes (Greenwald et al., 1985, 1995). HF backscatter radars obtain coherent echoes when the obliquely propagating radio waves achieve normal incidence with magnetic field-aligned irregularities. The fluid $\boldsymbol{E} \times \boldsymbol{B}$ (gradient drift) instability (see Tsunoda, 1988; Kelley, 1989) is the mechanism most often 
cited as the cause of 10-m scale irregularities observed in the F-region. Such irregularities are actually thought to be secondary instabilities driven by primary gradient drift instabilities acting at 100-m to 1-km scales (e.g. Jayachandran et al., 2000).

F-region decametre-scale irregularities are thought to drift at the $\boldsymbol{E} \times \boldsymbol{B} / B^{2}$ convection velocity (Villain et al., 1985). However, Hanuise et al. (1991) regarded all SuperDARN echoes observed at ranges $<500 \mathrm{~km}$ as E-region echoes. Some E-region irregularities are generated by the gradient drift instability and others by the two-stream instability (Fejer and Kelly, 1980). The velocity of the latter is limited by the ion acoustic speed. Thus, only some E-region irregularities will be drifting at the plasma convection velocity.

The Tasman International Geospace Environment Radar (TIGER) (Dyson and Devlin, 2000) is a SuperDARN radar located on Bruny Island, Tasmania $\left(147.2^{\circ} \mathrm{E}, 43.4^{\circ} \mathrm{S}\right.$ geographic; $-54.6^{\circ} \Lambda$ geomagnetic). Echo occurrence and motion-related statistics have been compiled for other radars in the SuperDARN network (Ruohoniemi et al., 1988; Leonard et al., 1995; Ruohoniemi and Greenwald, 1997; Nishitani et al., 1997; Milan et al., 1997b; Fukumoto et al., 1999; Hosokawa et al., 2000; Villain et al., 2002). However, TIGER is the most equatorward of the SuperDARN radars, both geographically and geomagnetically, extending the network coverage to include the midnight sub-auroral and auroral ionosphere for moderate levels of geomagnetic activity. Hence, TIGER is favourably located to study ionospheric substorms, and the accompanying narrow channels of large westward drift known as sub-auroral ion drifts (SAIDs) (Galperin et al., 1973; Anderson et al., 1991). We expect the statistics of TIGER echoes will contrast with those obtained with other SuperDARN radars.

In this paper we report the occurrence statistics and average motions of ionospheric irregularities observed using TIGER during the first year of operation, the sunspot maximum interval December 1999 to November, 2000. The majority of echoes observed using TIGER were "sea echoes" from the Southern Ocean ( $62 \%)$, but these have been excluded in this study. The remaining ionospheric echoes were sorted according to universal time (UT), magnetic local time (MLT), season, the geomagnetic activity index, $K_{p}$, and the interplanetary magnetic field (IMF) vector separated into the four basic quadrants of the $B_{y}-B_{z}$ plane. Wherever possible, the behaviour of echo parameters has been related to familiar magnetospheric boundaries and regions.

We report the average LOS Doppler velocities measured along the magnetic meridian (providing a direct indication of zonal electric fields) and Doppler velocity spread, or "spectral widths." The latter are an indication of the spread of irregularity motion within the sampling volume corresponding to individual beam-range cells. The spectral widths are thought to be enhanced by large-scale velocity gradients, convection turbulence, and Pc1-2 hydromagnetic wave activity. The importance of the latter was shown in simulations by André et al. (1999, 2000a, 2000b). However, Ponomarenko and Waters (2003) have subsequently found an error in the calculations of André et al. The cause of the large spectral widths is still an open question, but broad-band bursts of ULF wave activity, measured by an induction coil magnetometer located at Macquarie Island $\left(159.0^{\circ} \mathrm{E}, 54.5^{\circ} \mathrm{S}\right.$; $-65^{\circ} \Lambda$ ), are often synchronised with large spectral widths appearing at the same magnetic latitude in the field-of-view (FOV) of the TIGER radar (Parkinson et al., 2003).

The occurrence and motion of $10-\mathrm{m}$ scale irregularities observed with HF backscatter radars are determined by the product of various instrumental and geophysical factors (Ruohoniemi and Greenwald, 1997):

1. The design and operation of the radar, including the chosen pulse set and beam sequence, antenna pattern, the transfer function of all hardware elements, and any other factors affecting the radar gain versus frequency and direction, all affect the detection of echoes. The logic incorporated in the signal-processing methods used to recognise and characterise the echoes, and the subsequent procedures used to compile the statistics also influence the results.

2. The morphology of the ionospheric layers and the propagation modes they support (Milan et al., 1997b) determine whether the conditions for coherent backscatter are met. Spatial and temporal (diurnal, seasonal, and sunspot cycle) variations in non-deviative absorption (Davies, 1990), and focusing and defocusing of the HF rays by the ionosphere are also very important considerations. However, they are difficult to quantify without detailed ray tracing.

3. The generation of decametre-scale irregularities by different ionospheric instabilities and their subsequent dissipation is highly variable. Gradients in electron density associated with insolation, large-scale convection, particle precipitation, and atmospheric gravity waves must regulate the growth of $\boldsymbol{E} \times \boldsymbol{B}$ instabilities (Fejer and Kelley, 1980). Enhanced E-region conductivity due to insolation or precipitation increases dissipation of the irregularities via enhanced cross-field diffusion (Vickrey and Kelley, 1982).

Because of reasons 1 and 2, the echo occurrence rates are usually lower limits to actual irregularity occurrence rates.

\section{Observations and analysis}

Figure 1 shows the FOV of the TIGER radar mapped in geographic (left) and geomagnetic (right) coordinates. The bore sight of TIGER (beams 7/8) points geographic south, whereas beam 4 (bold) is closely aligned with the magnetic meridian $\left(226^{\circ} \mathrm{E}\right)$. In the fast (normal) common mode of operation, TIGER performs one sequential 16-beam scan from east (beam 15) to west (beam 0), integrating for $3 \mathrm{~s}(7 \mathrm{~s})$ on each beam. Hence, a full scan takes $48 \mathrm{~s}$ (112 s), with successive scans synchronised to the start of 1-min (2-min) bound- 


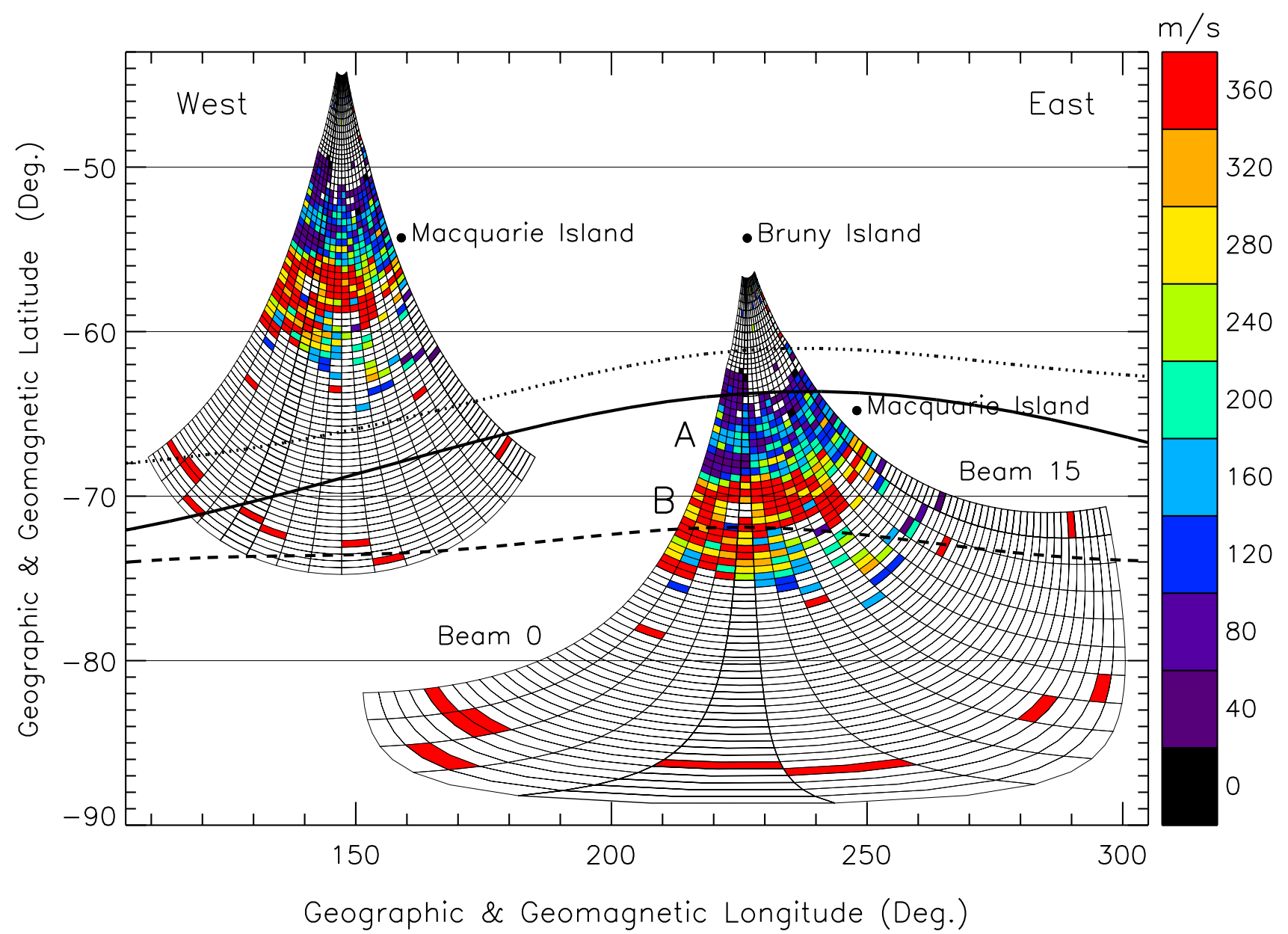

Fig. 1. The field-of-view (FOV) of the TIGER radar mapped to geographic (left) and geomagnetic coordinates (right), both drawn on the same grid to emphasise differences. The magnetic meridian pointing beam 4 and the eastern beam 15 are shown in bold. Shaded pixels represent ionospheric echoes with spectral widths $<200 \mathrm{~m} \mathrm{~s}^{-1}$ (light) and $>200 \mathrm{~m} \mathrm{~s}^{-1}$ (dark) recorded during the full scan commencing 17:16 UT on 5 September 2000. The location of auroral oval boundaries given by the Starkov (1994b) model for $A L=-172 \mathrm{nT}\left(K_{p}=3\right)$ are superimposed: poleward boundary of the discrete aurora (dashed curve), equatorward boundary of the discrete aurora (solid curve), and equatorward boundary of the diffuse aurora (dotted curve).

aries. Individual beams in the scan are separated by $3.24^{\circ}$, and the full scan spans $52^{\circ}$ of azimuth.

Figure 1 illustrates the large difference between the geographic and magnetic FOVs; some of the underlying dynamics will be characteristic of a high mid-latitude station (e.g. radio propagation, insolation, and D-region absorption), yet others will be characteristic of the sub-auroral, auroral, and polar cap ionosphere. Figure 1 also illustrates the presence of two separate populations of ionospheric echoes, "A" and "B", with low and high spectral widths, respectively, (to be defined). Model auroral oval boundaries given by Starkov (1994b) have been superimposed with beam 4 located at midnight MLT. The auroral electrojet index $A L=-172$ corresponding to $K_{p}=3$ used to drive the model was calculated using the conversion given by Starkov (1994a). The Starkov model has been tested against real data, but other models would give similar results.

If occurrence statistics were compiled for all 16 beams combined, it would be difficult separating geophysical and geometric dependencies. Hence, we compiled occurrence statistics for beams 4 and 15 (Fig. 1, bold), thereby revealing the most interesting aspects of data recorded on all beams. For example, beam 4 was chosen because it points down the magnetic meridian, providing an overview of dynamics occurring in the sub-auroral, auroral, and polar cap ionosphere $\left(-57^{\circ} \Lambda\right.$ to $\left.-88^{\circ} \Lambda\right)$. Assuming the $\boldsymbol{E} \times \boldsymbol{B} / B^{2}$ drift of Fregion irregularities, the corresponding LOS Doppler velocities were also a direct measure of zonal electric fields occurring along the meridian.

In contrast, beam 15 (bold) was chosen because its range window extends from latitude $-57^{\circ} \Lambda$ to $-72^{\circ} \Lambda$, providing a detailed view of the nightside sub-auroral and auroral ionosphere. Beam 15 becomes a zonal, eastward-looking beam at furthest ranges, reaching a maximum latitude of $-71.8^{\circ} \Lambda$ (range cell 68) before folding back toward the equator beyond this range. Thus, beams 4 and 15 are the two most 
Table 1. TIGER normal scan data analysed in this study

\begin{tabular}{llll}
\hline Summer 1999 and 2000 & Autumn 2000 & Winter 2000 & Spring 2000 \\
\hline 02-09, 19-31 December & 14-18, 27-29 February & 07-18, 24-31 May & 14-18, 23-24, 25-28 August \\
\hline 01-03, 13-13, 18-31 January & 01-04, 29-31 March & 01-04, 05-15, 21-26 June & 01-21 September \\
\hline 01-02 February & 05-06, 11-12, 14-23 April & 01-04, 05-06, 12-20 July & 03-17, 20-26 October \\
\hline 09-14, 20-30 November & 01-02 May & & 05-07 November \\
\hline
\end{tabular}

independent, nearly orthogonal beams in the FOV. Finally, beam 15 is located adjacent to Macquarie Island $\left(-65^{\circ} \Lambda\right)$, a key sub-Antarctic station supporting many ground-based instruments.

In this study we compiled statistics using all available, common mode data recorded during the sunspot maximum interval, December, 1999 to November, 2000. The actual dates of the measurements are shown in Table 1, subdivided into four seasons redefined to encompass $\sim 90$-day intervals centred on the equinoxes and solstices. This sorting emphasises the component of seasonal variability controlled by the solar-zenith angle, though other controls may dominate (Basu, 1975).

The radar control programs used to make the normal and fast mode soundings were "normal_scan_nodata" and "normal_scan3", respectively. We excluded most of the data recorded with other experimental programs to prevent introduction of statistical biases.

The default transmission frequency bands for normal_scan3 were 14.35 to $14.99 \mathrm{MHz}$ during the "day" (21:00 to 09:00 UT), and 11.65 to $12.05 \mathrm{MHz}$ during the "night" (09:00 to 21:00 UT). A clear frequency search was always performed within these individual frequency bands. However, normal_scan_nodata invoked a frequency search algorithm whenever fewer than 20 beam-range bins contained ionospheric echoes. The program then spent two minutes integrating on beam numbers $2,6,10$, and 14 at one frequency in each of five different licensed bands spread between 10.1 and $15.6 \mathrm{MHz}$. The frequency band with the largest number of ionospheric echoes was then adopted in subsequent scans until echoes were detected in fewer than 20 beam-range bins again. The program used the same default bands as normal_scan 3 whenever fewer than 5 echoes were detected during a frequency search.

Figure 2 is a histogram showing the roughly trimodal distribution of radar frequencies used throughout the entire study interval. The scale size of ionospheric irregularities corresponding to each of the three dominant peaks were 14.4, 12.3 , and $10.3 \mathrm{~m}$, respectively. If it were not for the effects of prohibited frequency bands (shaded), combined with the effects of narrow band interference, the histogram might approximate a bell-shaped or log-normal curve centred somewhere between 10 to $12 \mathrm{MHz}$. The latter is the known frequency of maximum radar gain.
Figure 3 shows the diurnal variation of the transmitter frequency averaged over 30-min intervals, with scatter bars superimposed. The daytime frequency tends to be $>1 \mathrm{MHz}$ larger, simply to compensate for greater refraction associated with higher daytime electron densities, and thereby increasing the probability of recording useful echoes at greater ranges. Note the resultant discontinuities near 08 and 19 MLT. Figures 2 and 3 are shown because they represent potential biases in our results.

In the common mode of operation, SuperDARN radars calculate the autocorrelation functions (ACFs) of echoes (Hanuise et al., 1993) digitised at 75 range gates starting at $180 \mathrm{~km}$ and separated by $45 \mathrm{~km}$ (i.e. 180 to $3555 \mathrm{~km}$ ). The $45-\mathrm{km}$ interval corresponds to the $300-\mu$ s width of transmitter pulses. The "FITACF" algorithm (Baker et al., 1995) processes the ACFs to estimate the echo power in logarithmic units of signal-to-noise ratio (i.e. dB), LOS Doppler velocity $\left(\mathrm{m} \mathrm{s}^{-1}\right)$, and the Doppler spectral width $\left(\mathrm{m} \mathrm{s}^{-1}\right)$, for all ranges on every beam. Our version of FITACF rejected echoes with $\mathrm{SNR}<3 \mathrm{~dB}$, flagging the remainder as sea echoes if the Doppler speeds and spectral widths were less than $50 \mathrm{~m} \mathrm{~s}^{-1}$ and $20 \mathrm{~m} \mathrm{~s}^{-1}$, respectively, and determined with small errors. In this study, ionospheric echoes were those defined as such by the FITACF algorithm. This identification is reliable in the majority of cases, but some ionospheric echoes are mistaken for ground echoes, and vice versa.

Results shown in the next section are presented in the form of contour plots of echo occurrence and average FITACF parameter versus time and range. Beam 4 results are shown in a standard clock dial format using altitude adjusted corrected geomagnetic coordinates (AACGM) (Baker and Wing, 1989). The range gates were mapped to AACGM latitude using the standard analysis procedure. This assumes a virtual reflection height of $300 \mathrm{~km}$, but with tapering to Eregion heights at ranges $<600 \mathrm{~km}$. The difference between MLT and UT for beam 4 was about 10 hours and $46 \mathrm{~min}$, but this difference changes rapidly approaching the geomagnetic pole, where the beam direction veers away from the magnetic meridian.

A total of 1666429 (1357310) ionospheric echoes were identified on 149377 (151310) separate beam 4 (beam 15) soundings, so the major features shown here are statistically significant. Occurrence rates were calculated by counting 


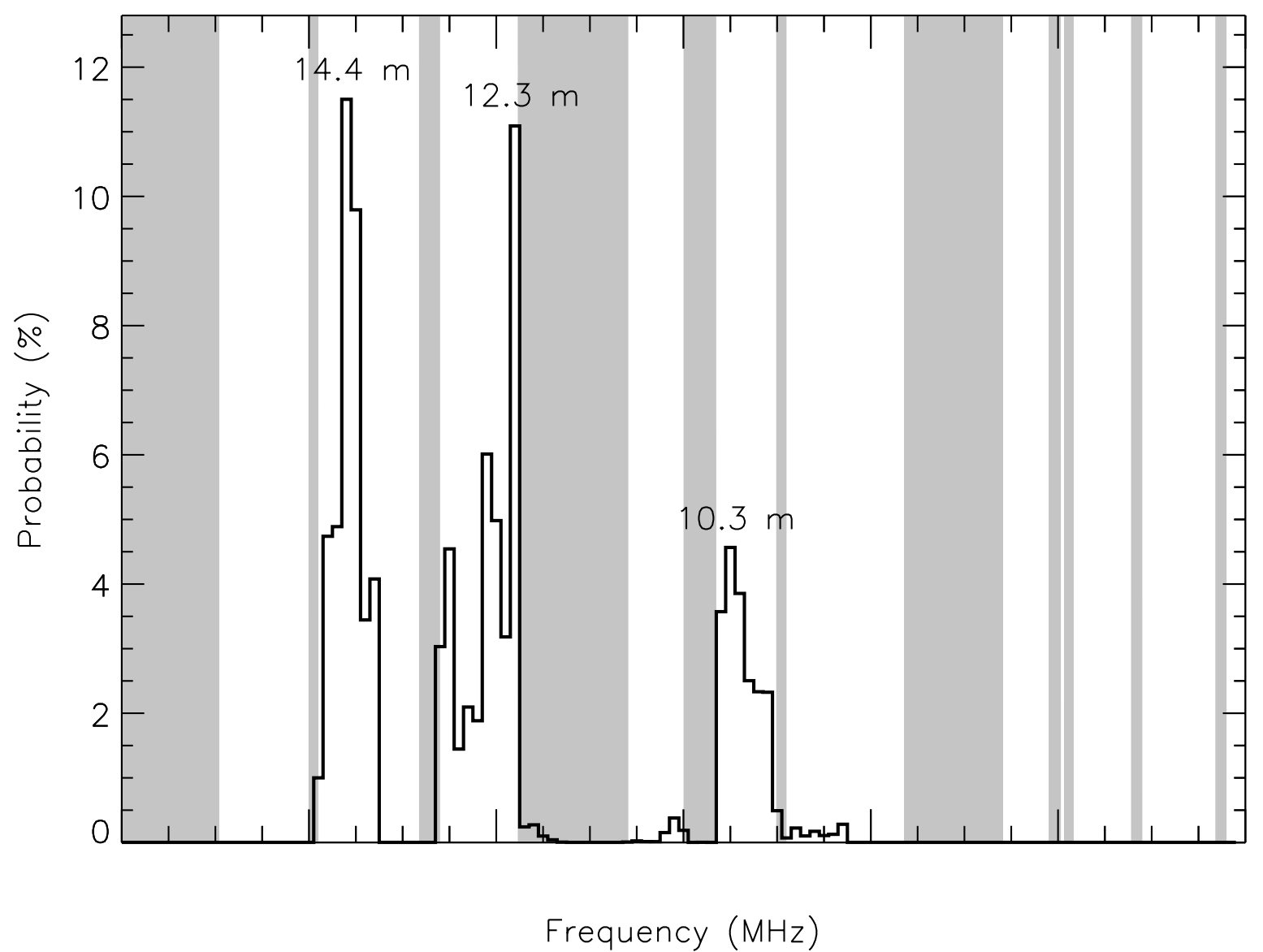

Fig. 2. Histogram showing the probability of the radar selecting a particular transmitter frequency during the study interval, December 1999 to November 2000. The radar electronics can operate anywhere between 8 and $20 \mathrm{MHz}$, but shaded regions correspond to frequency bands we never used because of our RF license restrictions.

the total number of echoes during 15 -min intervals of time at each of the 75 ranges, then dividing by the total number of soundings made for a particular category of season, $K_{p}$, or the IMF. Thus, 96 times $\times 75$ ranges $=7200$ occurrence rates were calculated for each map showing an average diurnal variation. The total number of echoes in each category was always divided by the actual number of soundings made. Hence, the occurrence rates are "self-normalising" with respect to the chosen category.

The $K_{p}$ index is determined using a network of midlatitude magnetometers, and is a measure of planetary geomagnetic activity. Ideally, measurements made using TIGER, a nightside auroral oval radar, should be sorted according to the $A L$ index (Davis and Sugiura, 1966), or a local $K$ index derived from the magnetometer located at Macquarie Island. Unfortunately, reliable $K$ or $A L$ indices were not available for this study.

Finally, the IMF data used in this study were 4-min averages measured on board the Atmospheric Composition Explorer (ACE) spacecraft which orbits the L1 libration point located $\sim 235$ Earth radii upstream of the Earth in the solar wind. The orthogonal IMF components $B_{y}$ and $B_{z}$ were expressed in the geocentric solar magnetospheric (GSM) coordinate system. The IMF components were advected from ACE to the Earth using the geocentric solar ecliptic $x$-location of the spacecraft and an average solar-wind speed of $370 \mathrm{~km} \mathrm{~s}^{-1}$. Although this method of advecting the solarwind conditions is approximate, the same basic statistical results would be obtained when using more refined procedures.

\section{Results}

\subsection{Beam 4 occurrence rates}

\subsubsection{Seasonal dependence}

Figure 4 shows the occurrence of beam 4 ionospheric echoes sorted according to season for all $K_{p}$ values. The colour key represents the colour for an occurrence rate of, say, $49 \%$ (red), which corresponds to occurrence rates in the range 47.5 to $50.5 \%$. Model auroral oval boundaries (Starkov, 1994b) have been superimposed in each panel using $A L=$ $-108 \mathrm{nT}$ (summer) (a), $-107 \mathrm{nT}$ (autumn) (b), $-131 \mathrm{nT}$ (winter) (c), and $-120 \mathrm{nT}$ (spring) (d). These values corre- 


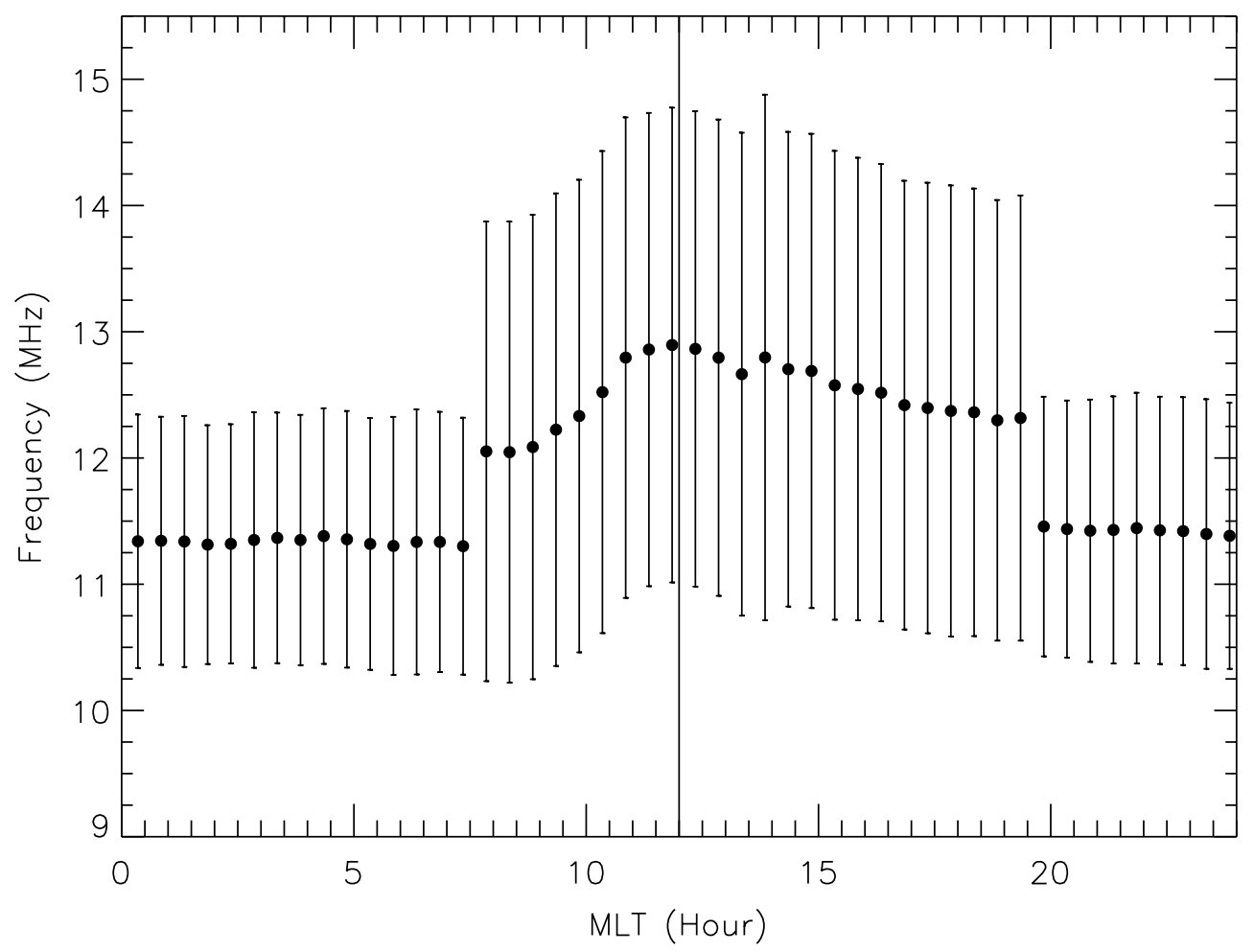

Fig. 3. The diurnal variation of transmitter frequency averaged over 30-min intervals of MLT during the study period, December 1999 to November 2000. The scatter bars correspond to \pm one standard deviation. The discontinuities in transmitter frequency at 07:46 and 19:46 MLT (21:00 and 09:00 UT) correspond to the transitions between default day and night frequency bands, respectively.

spond to the average $K_{p}$ values occurring when ionospheric soundings were made, namely $2.28 \pm 0.01,2.27 \pm 0.01,2.56$ \pm 0.01 , and $2.43 \pm 0.01$ in each season, respectively (standard errors are given). Note the poleward edge of the discrete auroral oval (dashed curve) delineates a fixed polar cap boundary, but the radar statistics encompass a broad range of geomagnetic activity. Hence, we expect the observed echo distributions to be smeared in latitude with respect to the model boundaries.

Similar patterns of echo occurrence were recorded during all seasons, but there were some intriguing differences. For example, the dominant band of echoes observed between $\sim-65^{\circ} \Lambda$ and $-76^{\circ} \Lambda$ during the night was confined between $\sim 20$ and 07 MLT during the summer (Fig. 4a), but extended between $\sim 16$ and 08 MLT during the winter (Fig. $4 \mathrm{c}$ ). The azimuthal extent of this enhanced echo occurrence was intermediate during the autumn (Fig. 4b) and spring (Fig. 4d). The regions of peak echo occurrence ( $>58 \%$; brown) were concentrated after midnight during summer and autumn, before midnight during winter, and nearly symmetric about midnight during spring. However, overall, more echoes were observed post-midnight than pre-midnight.

A lesser patch of mostly polar cap echoes was observed between $\sim-70^{\circ} \Lambda$ and $-82^{\circ} \Lambda$ on the dusk side, confined between $\sim 16$ and 21 MLT during the winter. The azimuthal extent of this feature contracted toward midnight during autumn and especially spring, and may have completely merged into the dominant band of nightside auroral echoes during summer. This feature was more distinct in beam 15 observations which showed its azimuthal extent contracted to $\sim 20$ and 23 MLT during summer. Corresponding peak occurrence rates were found most equatorward during the summer, but were largest and most poleward during the autumn.

Relatively few ionospheric echoes were detected in the "dayside ionosphere" (06 to 18 MLT), with occurrence rates mostly $<20 \%$. The minimum occurrence rates were centred on $\sim 13$ MLT during summer and winter, though closer to noon during autumn and spring. Maximum dayside occurrence rates were observed during winter, and to a lesser extent during autumn, as a consequence of the beforementioned polar cap echoes extending into the late afternoon. However, the peak occurrence rate was $\sim 46 \%$ for an isolated patch of echoes $\sim 1 \mathrm{~h}$ wide, centred near 08:40 MLT and $-78^{\circ} \Lambda$ during the winter. A similar feature was located near $-80^{\circ} \Lambda$ during autumn, but the peak occurrence rate dropped to $\sim 34 \%$. The occurrence rates were lowest of all for this feature during summer. When considering all seasons combined, very few ionospheric echoes were detected in the polar cap ionosphere poleward of $-80^{\circ} \Lambda$, but especially during 01 to 16 MLT.

Bands of occurrence rates generally $<16 \%$ were found between midnight and noon equatorward of $-61.8^{\circ} \Lambda$ (i.e. range $\leq 630 \mathrm{~km}$ ), whereas the occurrence rates were generally $<7 \%$ between noon and midnight at similar ranges. 

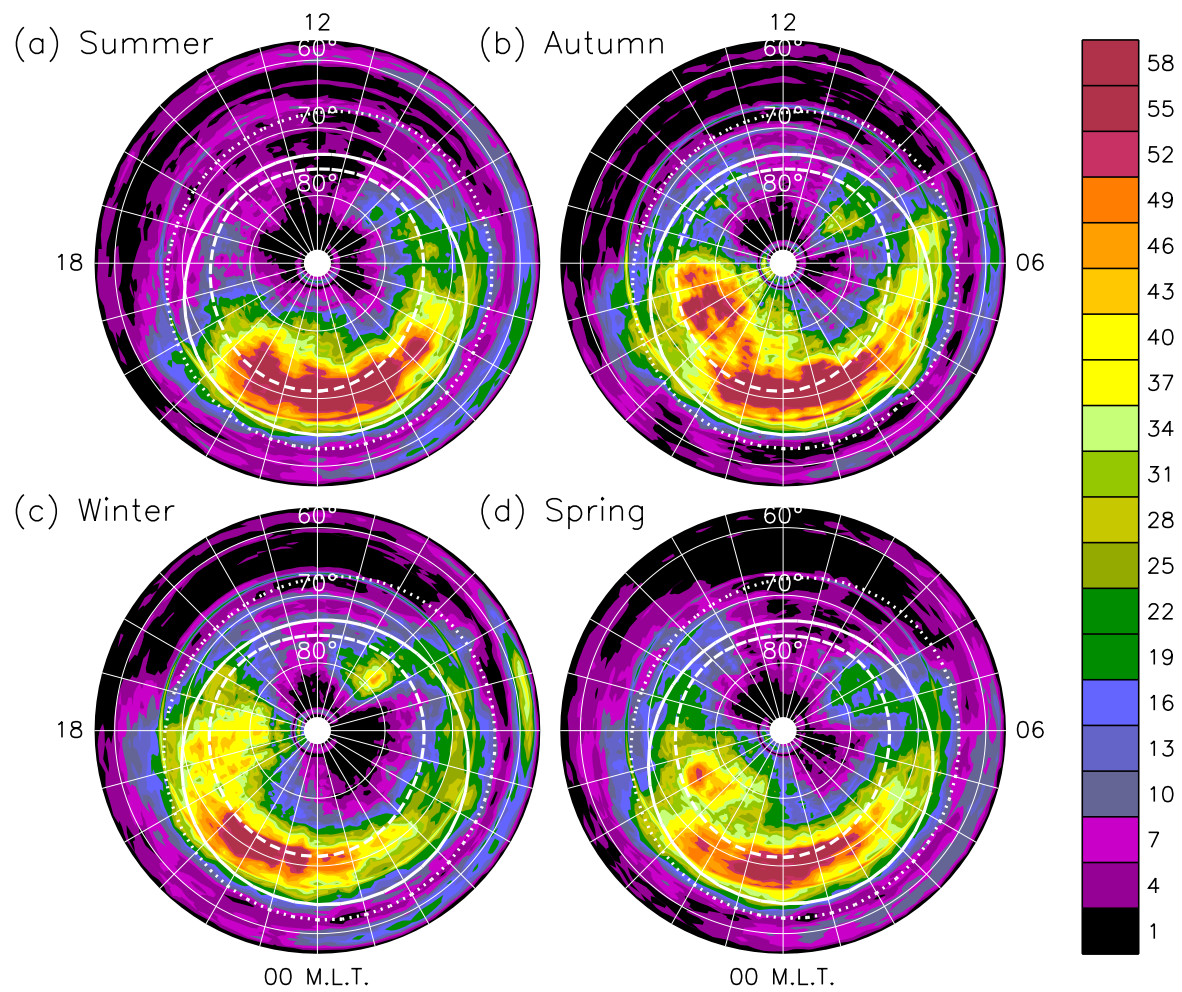

Fig. 4. The occurrence rate of beam 4 ionospheric echoes for all $K_{p}$ values detected during (a) summer (days 313 to 035), (b) autumn (days 036 to 126), (c) winter (days 127 to 221), and (d) spring (days 222 to 312). The results are shown versus MLT and magnetic latitude, with noon (12 MLT) at top, and dusk (06 MLT) at right, and the equatorward boundary at $-57^{\circ} \Lambda$. Magnetic latitudes $-60^{\circ},-70^{\circ}$, and $-80^{\circ} \Lambda$ have been superimposed. No data were acquired poleward of $-88^{\circ} \Lambda$. Model auroral oval boundaries have been superimposed (see text).

Table 2. Seasonal changes in beam 4 occurrence rates, range $>630 \mathrm{~km}$

\begin{tabular}{ccccc}
\hline & Summer & Autumn & Winter & Spring \\
\hline Total no. echoes & 384257 & 303488 & 457373 & 419371 \\
\hline Total no. beam soundings & 40702 & 24164 & 44311 & 40200 \\
\hline Average occurrence rate $(\%)$ & 13.70 & 18.68 & 15.60 & 15.01 \\
\hline Standard error $(\%)$ & 0.19 & 0.21 & 0.18 & 0.18 \\
\hline Peak occur. Rate $(\%)$ & 71 & 77 & 65 & 65 \\
\hline
\end{tabular}

The peak occurrence rate was $\sim 20 \%$ near 04:30 MLT during the summer, and $\sim 40 \%$ near 06:40 MLT during the winter. When the near-range occurrence rates were averaged for all seasons combined, they were roughly centred near 06 MLT.

The echoes responsible for the occurrence rates at close ranges exhibit the characteristics of meteor echoes (Hall et al., 1997), but echoes from E-region plasma instabilities associated with aurora and sporadic E must also contribute. The corresponding irregularities do not necessarily drift at the ion convection velocity (Hanuise et al., 1991). Hence, in the following analysis we separate echoes into two groups, namely those echoes at ranges $\leq 630 \mathrm{~km}$ and those echoes at ranges $>630 \mathrm{~km}$. The latter are thought to correspond to upper E- and F-region irregularities drifting at the ion convection velocity (Villain et al., 1985).

Table 2 shows the total number of echoes observed in each season, the total number of beam 4 soundings in each season, the average occurrence rates, their standard errors, and the peak occurrence rates, all for ranges $>630 \mathrm{~km}$. Variability in the total number of soundings reflects upon equipment failures (computer crashes, power failures, etc.). There are 64 range bins at ranges $>630 \mathrm{~km}$. Hence, the average occurrence rate $(\%)$ is the average of the 96 times $\times 64$ ranges $=6144$ occurrence rates calculated for each season. This average does not equal the total number of echoes divided by the total number of beam soundings, because there was a dif- 
Table 3. Seasonal changes in beam 4 occurrence rates, range $\leq 630 \mathrm{~km}$

\begin{tabular}{ccccc}
\hline & Summer & Autumn & Winter & Spring \\
\hline Total no. echoes & 31794 & 14293 & 33673 & 22180 \\
\hline Total no. beam soundings & 40702 & 24164 & 44311 & 40200 \\
\hline Average occurrence rate $(\%)$ & 6.57 & 4.92 & 6.60 & 4.44 \\
\hline Standard error $(\%)$ & 0.16 & 0.14 & 0.20 & 0.10 \\
\hline Peak occur. Rate $(\%)$ & 23 & 25 & 38 & 14 \\
\hline
\end{tabular}

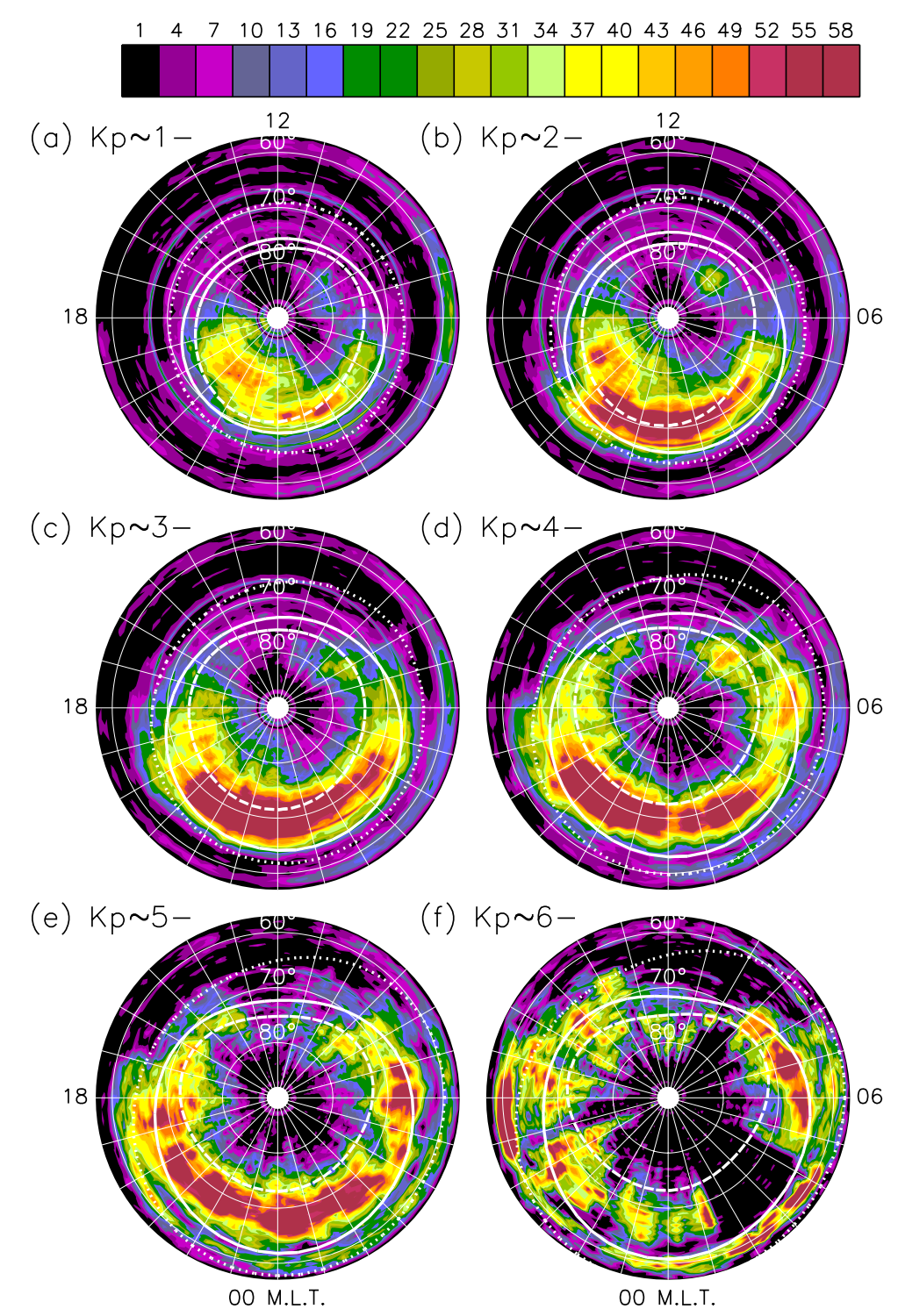

Fig. 5. The occurrence rate of beam 4 ionospheric echoes detected during all seasons, and sorted according to geomagnetic activity. (a) $K_{p}=0$ to 1 , (b) $K_{p}>1$ to 2 , (c) $K_{p}>2$ to 3 , (d) $K_{p}>3$ to 4 , (e) $K_{p}>4$ to 5 , and (f) $K_{p}>5$ to 6 . Model auroral oval boundaries for (a) $A L=-21 \mathrm{nT}\left(K_{p} \approx 1-\right)$, (b) $A L=-64 \mathrm{nT}\left(K_{p} \approx 2-\right)$, (c) $A L=-141 \mathrm{nT}\left(K_{p} \approx 3-\right)$, (d) $A L=-240 \mathrm{nT}\left(K_{p} \approx 4-\right)$, (e) $A L=-350 \mathrm{nT}\left(K_{p} \approx 5-\right)$, and (f) $A L=-458 \mathrm{nT}\left(K_{p} \approx 6-\right)$ have been superimposed. 
Table 4. Geomagnetic changes in beam 4 occurrence rates, range $>630 \mathrm{~km}$

\begin{tabular}{ccccccc}
\hline$K_{p}$ & $0-1$ & $>1-2$ & $>2-3$ & $>3-4$ & $>4-5$ & $>5-6$ \\
\hline Total no. echoes & 272966 & 417971 & 440474 & 257342 & 117522 & 30387 \\
\hline Total no. beam soundings & 30901 & 40447 & 39682 & 22412 & 10018 & 3462 \\
\hline Average occurrence rate $(\%)$ & 11.71 & 15.43 & 17.01 & 17.22 & 17.56 & 12.34 \\
\hline Standard error $(\%)$ & 0.16 & 0.20 & 0.22 & 0.23 & 0.23 & 0.20 \\
\hline Peak occur. Rate $(\%)$ & 56 & 74 & 80 & 85 & 74 & 82 \\
\hline
\end{tabular}

ferent number of soundings in each of the 15-min intervals and 64 ranges. The standard errors $(\%)$ were calculated by dividing the standard deviations of the occurrence rates by $\sqrt{6144}$. The peak occurrence rate is simply the maximum occurrence rate of the 6144 occurrence rates.

Table 2 shows that the largest number of echoes was recorded during winter, then spring, summer, and least of all during autumn. However, because of the different number of beam soundings made per season, the average occurrence rate was largest for autumn, next largest for winter, then spring, and least of all for summer (cf. Fig. 4). On the other hand, peak occurrence rates were largest in autumn, then summer, and then the same during spring and winter. Variations in the averages are more meaningful than variations in the peak values. The standard errors for the averages show that the seasonal changes were statistically significant, but systematic biases not related to the occurrence of ionospheric irregularities may be present.

Table 3 compiles the same information as Table 2, except it shows the statistics for echoes at ranges $\leq 630 \mathrm{~km}$. There are 11 range bins at ranges $\leq 630 \mathrm{~km}$, so an average occurrence rate is the average of 96 times $\times 11$ ranges $=1056$ occurrence rates. The occurrence rates were largest $(\sim 6.6 \%)$ and equal within error limits during summer and winter, and $\sim 2 \%$ lower and comparable during autumn and spring. The peak occurrence rates were largest during winter and least during spring, and similar during summer and autumn. The peak occurrence of $38 \%$ occurred at $~ 07$ MLT during winter (cf. Fig. 4c). In passing, we note this seasonal variation is very similar to the seasonal variation of meteor echoes observed at Halley Base, Antarctica (Jenkins et al., 1998).

Lastly, the transmitter pulse set was designed to minimise the detrimental effects of range aliasing. However, the narrow, circular striations in all panels of Fig. 4 (e.g. the prominent ring at $\sim-67^{\circ} \Lambda$ ) correspond to bad ranges in the ACFs calculated using the chosen pulse sequence.

\subsubsection{Geomagnetic activity dependence}

Figure 5 shows the occurrence rates of ionospheric echoes for all seasons combined and sorted according to the geomagnetic activity index $K_{p}$. As in Fig. 4, peak occurrence rates were usually observed in the nightside auroral and po- lar cap ionosphere between $-65^{\circ} \Lambda$ and $-76^{\circ} \Lambda$. However, for quiet conditions, $K_{p}=0$ to 1 (a), the patch of mostly polar cap echoes found between 18 and 01 MLT and $-73^{\circ} \Lambda$ and $-82^{\circ} \Lambda$ contained a comparable number of echoes to the band found further equatorward between 22 and 05 MLT, and $-70^{\circ} \Lambda$ and $-76^{\circ} \Lambda$. For $K_{p}>1$ to 2 (b) the polar cap feature still contained many echoes, but fewer than the main band of auroral and polar cap echoes. The latter expanded to between 20:30 to 05:00 MLT and $-66^{\circ} \Lambda$ and $-76^{\circ} \Lambda$. For $K_{p}>2$ to 3 (c) and more disturbed conditions (d, e, f) the polar cap feature became indistinguishable as the main band of auroral echoes expanded in longitude and latitude, even extending into the dayside ionosphere.

Overall, peak occurrence rates tended to shift equatorward with $K_{p}$, as did the equatorward boundary of the model auroral oval. However, the peak occurrence rates were partly "trapped" in the latitude range $-63^{\circ} \Lambda$ to $-76^{\circ} \Lambda$, until very disturbed conditions, $K_{p}>4$ to 5 (e), when a horseshoe of echoes almost completely encircled the polar cap. For the most disturbed conditions of all, $K_{p}>5$ to 6 (f), there was a lot of E- and F-region scatter at close ranges, and scatter from both close and far ranges became very patchy, but locally intense.

Table 4 is in the same format as Table 2, except it shows the changes in average and peak occurrence rates with the $K_{p}$ index. The average occurrence rate was smallest during the quietest conditions (Fig. 5a), it grew to a maximum for $K_{p}>4$ to 5 (cf. Fig. 5e), and thereafter (Fig. 5f) fluctuated with increasing $K_{p}$. For example, the average occurrence rate was $20.2 \%$ for $K_{p}>6$ to 7 , then $12.8 \%$ for $K_{p}>$ 7 to 8 , etc. During the most disturbed intervals (Fig. 5f), the auroral oval began to expand equatorward of the 0.5-hop range window. Auroral E echoes must have begun to mask meteor echoes at close ranges, as well as F-region scatter at greater ranges.

Although not apparent in Table 4, the peak occurrence rates trended from $56 \%$ for the quietest intervals to $100 \%$ during more disturbed intervals (not listed). This is because the occurrence rates were calculated using a smaller and smaller number of intervals encompassing larger and larger geomagnetic storms. Hence, one sees the patchy distribution of echoes in Fig. 5f. Statistics for echoes at close ranges $\leq 630 \mathrm{~km}$ are not shown because there was no significant de- 


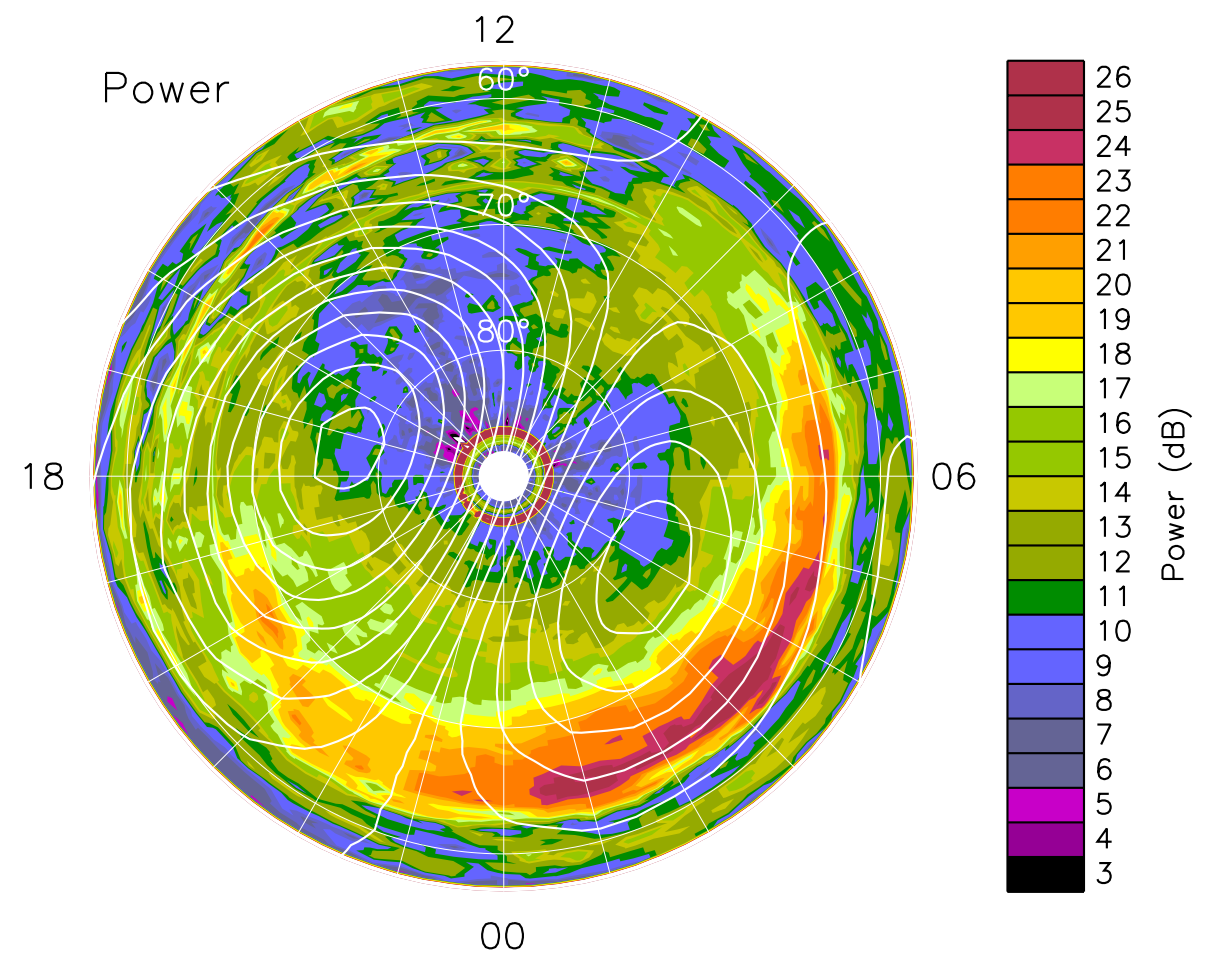

Fig. 6. Average power of ionospheric echoes with SNR $>3 \mathrm{~dB}$ recorded on beam 4 for all seasons and levels of geomagnetic activity combined. Equipotential contours calculated using the DICM model (see text) have been superimposed. The minimum electric potential in the dusk cell is $-23.4 \mathrm{kV}$, the maximum potential in the dawn cell is $11.3 \mathrm{kV}$, and contours are separated by $2.5 \mathrm{kV}$.

pendency on geomagnetic activity until $K_{p}>5$.

\subsection{Beam 4 average FITACF parameters}

\subsubsection{Average powers}

Figure 6 shows a map of the average power returned by the FITACF algorithm for ionospheric echoes with SNR $>3 \mathrm{~dB}$, and for all seasons and levels of geomagnetic activity combined. When the powers were sorted according to season and $K_{p}$, similar variations to those for the occurrence rates were found (e.g. an equatorward expansion with $K_{p}$ ). Average FITACF parameters are not shown in this and subsequent plots if fewer than 2 valid FITACF results were obtained per range-time bin. Thus, many of the small-scale fluctuations are a measure of statistical uncertainty.

Average IMF components for the entire data base were $\left(B_{x}, B_{y}, B_{z}\right)=(0.0,0.6,-0.1 \mathrm{nT})$. These values were used to drive the DMSP satellite-based Ionospheric Convection Model (DICM) (Papitashvili and Rich, 2002) which outputs high-latitude electric potentials. The results have been superimposed as equipotential contours representing streamlines of ionospheric flow velocity. In Fig. 6, the flow direction is clockwise in the dusk cell and anticlockwise in the dawn cell, resulting in nearly antisunward flow across the central polar cap.

Figure 6 shows that the main band of echo power $>18 \mathrm{~dB}$ occurred between 19 and 08 MLT and $-62^{\circ} \Lambda$ and $-72^{\circ} \Lambda$. Larger echo power $>20 \mathrm{~dB}$ occurred between 23 and 07 MLT and equatorward of $-70^{\circ} \Lambda$. The maximum in the distribution was centred near 02:45 MLT. The exception was winter when the maximum power was centred on midnight. The echo power increased rapidly at the equatorward edge of the main band $\left(\sim-62^{\circ} \Lambda\right)$, maximised at $\sim-64^{\circ} \Lambda$, and thereafter gradually decreased toward the geomagnetic pole. Minimum average power of $9 \mathrm{~dB}$ occurred in the dayside ionosphere between 11 and 16 MLT, diametrically opposite of the region of maximum power. Overall, the distribution of power was rotated further dawnward and $\sim 3^{\circ} \Lambda$ equatorward of the main echo occurrence shown in Fig. 4.

\subsubsection{LOS Doppler velocities}

Figure 7 shows the average LOS Doppler velocities sorted into four categories of the IMF vector in the $B_{y}-B_{z}$ plane, namely $B_{y}$ negative, $B_{z}$ positive (a), $B_{y}$ positive, $B_{z}$ positive (b), $B_{y}$ negative, $B_{z}$ negative (c), and $B_{y}$ positive, $B_{z}$ negative (d). By "positive" and "negative" we mean the IMF components were $>0.5 \mathrm{nT}$ and $<-0.5 \mathrm{nT}$, respectively. The corresponding average IMF components $\left(B_{x}, B_{y}, B_{z}\right)$ were $(1.9,-4.0,3.5 \mathrm{nT})(\mathrm{a}),(-1.8,4.6,3.6 \mathrm{nT})(\mathrm{b}),(1.9$, $-4.0,-3.6 \mathrm{nT})(\mathrm{c})$, and $(-1.7,4.5,-3.6 \mathrm{nT})(\mathrm{d})$, respectively. These values were used to drive the DICM and to obtain the equipotentials superimposed in all parts. The flow direction is clockwise in the weak afternoon cell in part (a), and anticlockwise in the weak morning cell in part (b). Sun- 


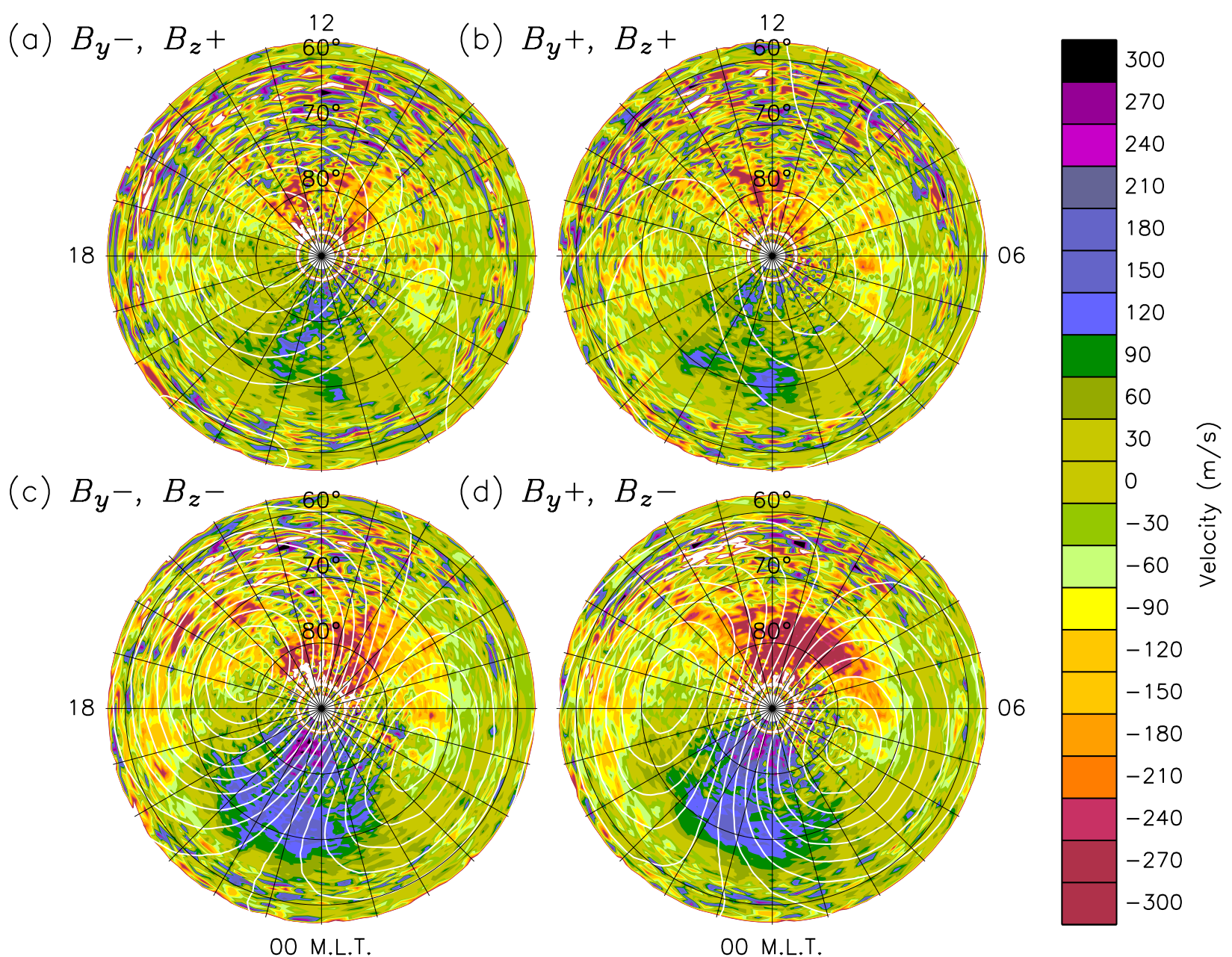

Fig. 7. Average LOS Doppler velocities recorded on beam 4 and sorted into four categories of the IMF in the $B_{y}-B_{z}$ plane: (a) $B_{y}$ negative, $B_{z}$ positive, (b) $B_{y}$ positive, $B_{z}$ positive, (c), $B_{y}$ negative, $B_{z}$ negative, and (d) $B_{y}$ positive, $B_{z}$ negative. Equipotential contours calculated using the DICM model have also been superimposed. Minimum and maximum potentials occurring in the patterns are as follows: (a) $-24.2 \mathrm{kV}$ in the weak afternoon cell, (b) $9.5 \mathrm{kV}$ in the weak morning cell, (c) $-52.8 \mathrm{kV}$ in the dusk cell and $26.8 \mathrm{kV}$ in the dawn cell, and (d) $-38.0 \mathrm{kV}$ in the dusk cell and $31.2 \mathrm{kV}$ in the dawn cell. Contours are separated by $5 \mathrm{kV}$.

ward flows are known to occur more often in the dayside ionosphere under $B_{z}$ northward conditions.

Figure 7 basically shows that the familiar cross polar jet was most developed for $B_{z}$ negative conditions (c), (d). Note the dayside region of large poleward velocities (brown; $\sim<-240 \mathrm{~m} \mathrm{~s}^{-1}$ ) was most extensive for $B_{y}$ positive conditions (d). These velocities correspond to flows entering the convection throat during 08 to 14 MLT at $\sim-78^{\circ} \Lambda$. The nightside region of large equatorward velocities (purple; $\sim 240 \mathrm{~m} \mathrm{~s}^{-1}$ ) was most extensive for $B_{y}$ negative conditions (c). These velocities correspond to flows exiting the polar cap during 21 to 24 MLT. They produced the extensive regions of moderate, equatorward LOS velocity (blue; $\sim 120 \mathrm{~m} \mathrm{~s}^{-1}$ ) during 19 to 02 MLT poleward of $\sim-68^{\circ} \Lambda$.

When sorted according to season, the maps of average LOS Doppler velocity show variations similar to those in Fig. 7. However, the region of large poleward velocities centred in the pre-noon sector were clearly more extensive during summer, then spring, winter, and least of all during autumn.

\subsubsection{Doppler spectral widths}

Figure 8 shows the average Doppler spectral widths for all seasons and levels of geomagnetic activity combined. The tendency for small and large spectral widths to sometimes alternate in bands separated by $\sim 3^{\circ} \Lambda$ wide is probably an artifact associated with the pulse set used to measure the $\mathrm{ACFs}$, and the numbers subsequently returned by the FITACF algorithm. Ideally, these artifacts should be quantified by modelling the pulse set behaviour, and then deconvolved from the observations. However, all the major features to be described were geophysical and reproducible using subsets of the entire data base.

The largest spectral widths, $>350 \mathrm{~m} \mathrm{~s}^{-1}$ (brown), were concentrated in the pre-noon polar cap ionosphere at 


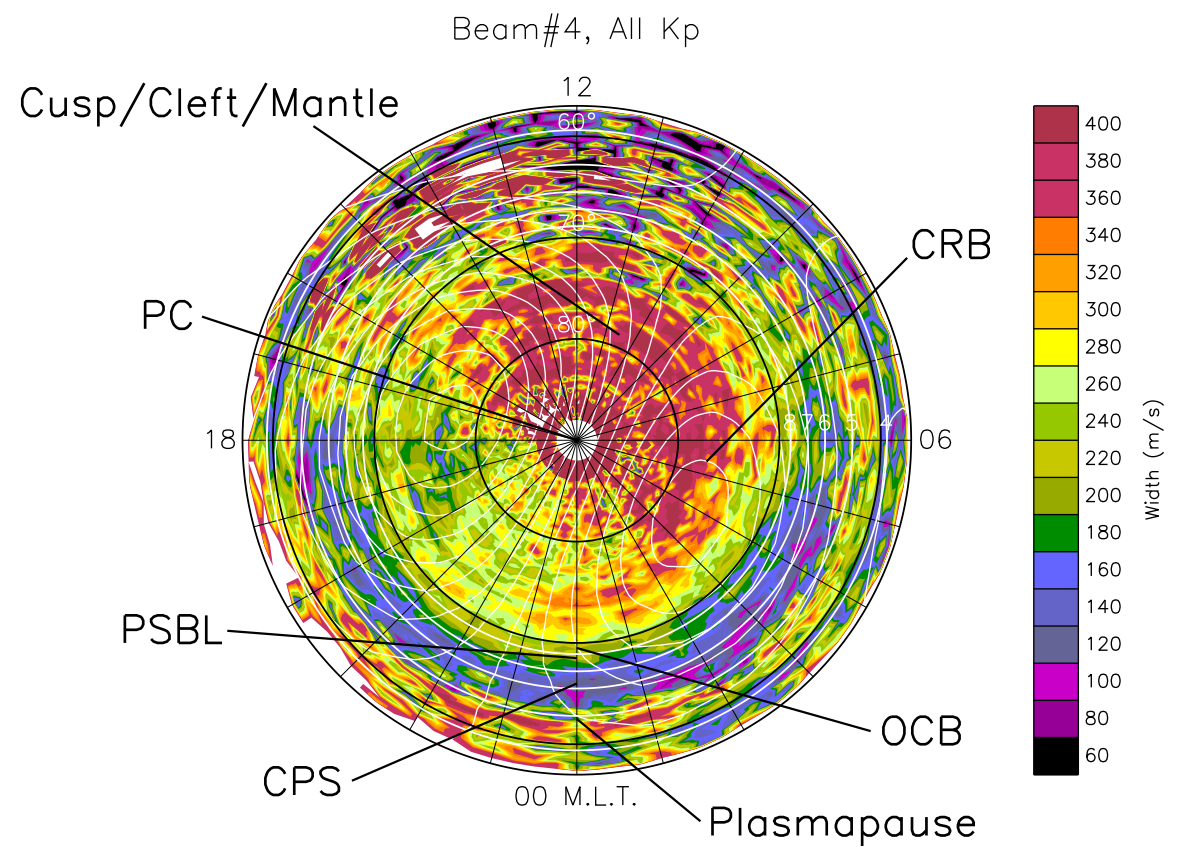

Fig. 8. Average Doppler spectral widths recorded on beam 4 for all seasons and $K_{p}$ values combined. Magnetic Lshells of $4,5,6,7$, and 8 have been superimposed, as well as the same equipotential contours superimposed in Fig. 6. $\sim-80^{\circ} \Lambda$. However, an arc of large spectral widths $>300 \mathrm{~m} \mathrm{~s}^{-1}$ (orange) extended into the nightside ionosphere between 23 and 06 MLT. The spectral widths declined quickly equatorward of $-73^{\circ} \Lambda$ near noon (and $-70^{\circ} \Lambda$ near dawn), whereupon they were $<160 \mathrm{~m} \mathrm{~s}^{-1}$ (blue) across much of the remaining dayside ionosphere. Similarly, the nightside spectral widths declined quickly near midnight, decreasing from $\sim 260 \mathrm{~m} \mathrm{~s}^{-1}$ at $-70^{\circ} \Lambda$ to $\sim 100 \mathrm{~m} \mathrm{~s}^{-1}$ equatorward of $-67^{\circ} \Lambda$. There was a significant "bite out" in spectral widths to values $<220 \mathrm{~m} \mathrm{~s}^{-1}$ centred on dusk, but extending from 15 to 21 MLT poleward of $67^{\circ} \Lambda$.

There was an $\sim 2$ to $3^{\circ} \Lambda$ wide "trough" in spectral width $\left(<160 \mathrm{~m} \mathrm{~s}^{-1}\right.$ ) centred on $\sim-66^{\circ} \Lambda$ and nearly encircling the entire $24 \mathrm{~h}$ of MLT. The spectral widths again increased to values $>160 \mathrm{~m} \mathrm{~s}^{-1}$ equatorward of $-63^{\circ} \Lambda$, especially between 16:00 and 01:30 MLT. A thin band of large spectral widths $>200 \mathrm{~m} \mathrm{~s}^{-1}$ was centred pre-dawn, between 02:30 to 07:30 MLT and $-60^{\circ} \Lambda$ and $-63^{\circ} \Lambda$.

When the results shown in Fig. 8 were sorted according to season (not shown), similar relative variations were apparent. However, there was a significant change in the extent of the pre-noon region with large spectral widths, from most extensive during spring, then summer, winter, and least of all during autumn. During spring the region of average spectral width $>240 \mathrm{~m} \mathrm{~s}^{-1}$ extended in longitude to encompass the high-latitude ionosphere poleward of $-70^{\circ} \Lambda$, except within $\sim 17$ to 21 MLT.

When the results shown in Fig. 8 were sorted according to $K_{p}$ (not shown), the spectral widths behaved similar to the occurrence of echoes (Fig. 5). The relative variations in spectral width were most like the Fig. 8 variations for moderately disturbed conditions, $K_{p}=2+$ to 3 . For $K_{p}=0$ to 1 , the region of large spectral widths $>300 \mathrm{~m} \mathrm{~s}^{-1}$ was concentrated in the sector 23 to 07 MLT at $\sim-74^{\circ} \Lambda$. As $K_{p}$ increased the regions of large spectral width expanded into the prenoon polar cap ionosphere, and equatorward. For the most disturbed conditions, there was a strong tendency for the regions of large spectral width to expand further until there was an almost symmetric distribution about the AACGM pole. However, there was still evidence for the dusk bite out.

When the results shown in Fig. 8 were sorted according to the IMF (not shown), the high-latitude regions of large spectral widths were least extensive for $B_{y}$ positive, $B_{z}$ positive, and most extensive for $B_{y}$ negative, $B_{z}$ negative. The dusk bite out in spectral width was also more prevalent for $B_{z}$ positive.

Finally, Fig. 8 is annotated with the approximate locations of some important magnetospheric boundaries and regions. These annotations will be discussed in Sect. 4.3.

\subsection{Beam 15 occurrence rates}

Figure 1 shows how beam 15 provided a detailed view of the nightside sub-auroral and auroral ionosphere, becoming an eastward-looking beam very sensitive to zonal flows at the furthest ranges. Occurrence statistics for beam $15 \mathrm{ob}-$ servations were presented by Parkinson et al. (2002a). Here we further analyse beam 15 observations in the context of beam 4 observations, to investigate the behaviour of ionospheric scatter with very low spectral width.

First consider Fig. 9 which shows histograms of echo occurrence versus Doppler spectral width recorded on beam 15 (solid curve) and beam 4 (dotted curve) for all seasons and levels of geomagnetic activity combined. More echoes were observed on beam 4 than beam 15 (660 646 versus 624051 ). For each beam there were two distinct populations of ionospheric echoes, "A" and "B". Population A included echoes 


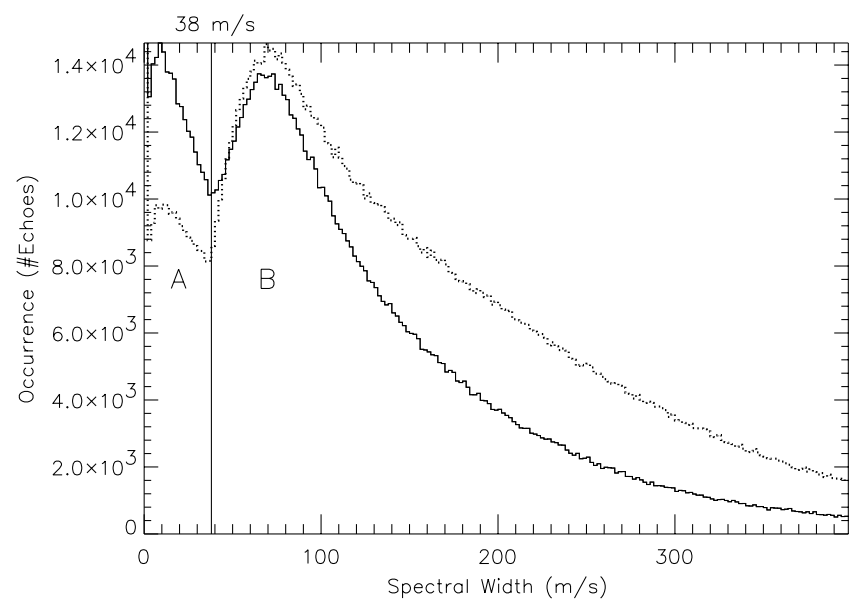

Fig. 9. Histograms of the number of ionospheric echoes versus Doppler spectral width recorded on beam 15 (solid curve) and beam 4 (dotted curve) during all seasons and $K_{p}$ values combined. A bin size of $2 \mathrm{~m} \mathrm{~s}^{-1}$ was used.

with low spectral width $<38 \mathrm{~m} \mathrm{~s}^{-1}$ and had a mode value of $\sim 9 \mathrm{~m} \mathrm{~s}^{-1}$ (bin size of $2 \mathrm{~m} \mathrm{~s}^{-1}$ ). They constituted $16.7 \%$ and $9.8 \%$ of the echoes observed using beam 15 and beam 4 , respectively. Population B included echoes with moderate to very large spectral width $\geq 38 \mathrm{~m} \mathrm{~s}^{-1}$, and had a mode value of only $\sim 70 \mathrm{~m} \mathrm{~s}^{-1}$.

Although the distribution functions for populations A and B must overlap, population A was completely dominant beneath the critical value $38 \mathrm{~m} \mathrm{~s}^{-1}$. More echoes with spectral width $<38 \mathrm{~m} \mathrm{~s}^{-1}$ were recorded on beam 15 , and more echoes with spectral width $>38 \mathrm{~m} \mathrm{~s}^{-1}$ were recorded on beam 4. Population A, in particular, may have been contaminated by sea echoes.

Figure 10 compiles the occurrence of population A echoes observed on beam 15 versus UT and group range, with corresponding magnetic latitudes superimposed. The observations were compiled in this way to emphasise variations due to changing propagation conditions. These would be less apparent if the results were compiled in the polar plot form of beam 4 , because beam 15 traverses $68^{\circ}$ of longitude $(\sim 4.5 \mathrm{~h}$ of MLT), and only achieves a maximum poleward latitude of $-71.8^{\circ} \Lambda$.

Nominal values of MLT in the ionosphere above Macquarie Island, located just to the east of beam 15, are shown at the top of Fig. 10. Similar to Fig. 4, model auroral oval boundaries are also superimposed in each panel using $A L=-109 \mathrm{nT}(\mathrm{a}),-108 \mathrm{nT}(\mathrm{b}),-131 \mathrm{nT}$ (c), and $-120 \mathrm{nT}$ (d). These values correspond to the average $K_{p}$ values occurring when beam 15 soundings were made, namely $2.30 \pm$ 0.01 (a), $2.28 \pm 0.01$ (b), $2.56 \pm 0.01$ (c), and $2.43 \pm 0.01$ (d).

Figure 10 shows that the occurrence of population A echoes observed on beam 15 was similar to the occurrence of echoes with any spectral width on beam 4 (Fig. 4). However, the peak occurrence rates were displaced further toward
Table 5. Seasonal changes in population A echoes, beam 15, range $>630 \mathrm{~km}$

\begin{tabular}{ccccc}
\hline & Summer & Autumn & Winter & Spring \\
\hline Total no. echoes & 76880 & 68038 & 96532 & 67443 \\
\hline Total no. beam soundings & 40231 & 26214 & 44384 & 40481 \\
\hline Average occurrence rate $(\%)$ & 2.44 & 3.58 & 2.93 & 2.07 \\
\hline Standard error $(\%)$ & 0.05 & 0.06 & 0.05 & 0.04 \\
\hline Peak occur. Rate $(\%)$ & 27 & 36 & 21 & 23 \\
\hline
\end{tabular}

dawn and the equator than in Fig. 4. Specifically, the main band of echoes observed on beam 15 ( $>8 \%$; karki) was concentrated between 23 and 07 MLT and $-63^{\circ} \Lambda$ and $-67^{\circ} \Lambda$. Hence, these echoes were mainly concentrated in the postHarang diffuse auroral oval, but also in the discrete auroral oval and sub-auroral ionosphere. Very few of these echoes were from the polar cap ionosphere.

Like the occurrence of echoes recorded on beam 4 (Fig. 4), the azimuthal extent of the dominant band of echoes observed on beam 15 was least during summer, greatest during winter, and intermediate during autumn and spring. A lesser patch of mostly auroral oval echoes was observed between $-65^{\circ} \Lambda$ and $-72^{\circ} \Lambda$ on the dusk side, confined between $\sim 15$ and 21 MLT during the winter. The azimuthal extent of this feature contracted toward midnight during autumn and spring, and most of all during summer.

The bands of echoes observed with occurrence rates mostly $<6 \%$ equatorward of $-60^{\circ} \Lambda$ correspond to backscatter from meteor trails, as well as E- and F-region plasma instabilities associated with aurora and sporadic-E.

Table 5 shows the total number of population A echoes (spectral width $<38 \mathrm{~m} \mathrm{~s}^{-1}$ ) observed at ranges $>630 \mathrm{~km}$ in each season, the total number of beam 15 soundings in each season, the average occurrence rates, their standard errors, and the peak occurrence rates. Because we are only considering echoes with a spectral width $<38 \mathrm{~m} \mathrm{~s}^{-1}$, the occurrence rates are much lower than those given for beam 4 (Table 2). The average occurrence rates were largest for beam 15 during autumn, then winter, summer, and least of all for spring. On the other hand, peak occurrence rates were largest in autumn, then summer, spring, and winter.

\subsection{Beam 15 average LOS Doppler velocity}

Figure 11 shows the average LOS Doppler velocities for beam 15 ionospheric echoes with any spectral width and $K_{p}$ value. The results have been sorted according to season, and the same model auroral oval boundaries used in Fig. 10 have been superimposed. The dominant feature in all seasons is the transition from large approaching (blue) to large receding (brown) Doppler velocities centred near 22 MLT at $-70^{\circ} \Lambda$, but occurring later at closer ranges (lower latitude). This fea- 


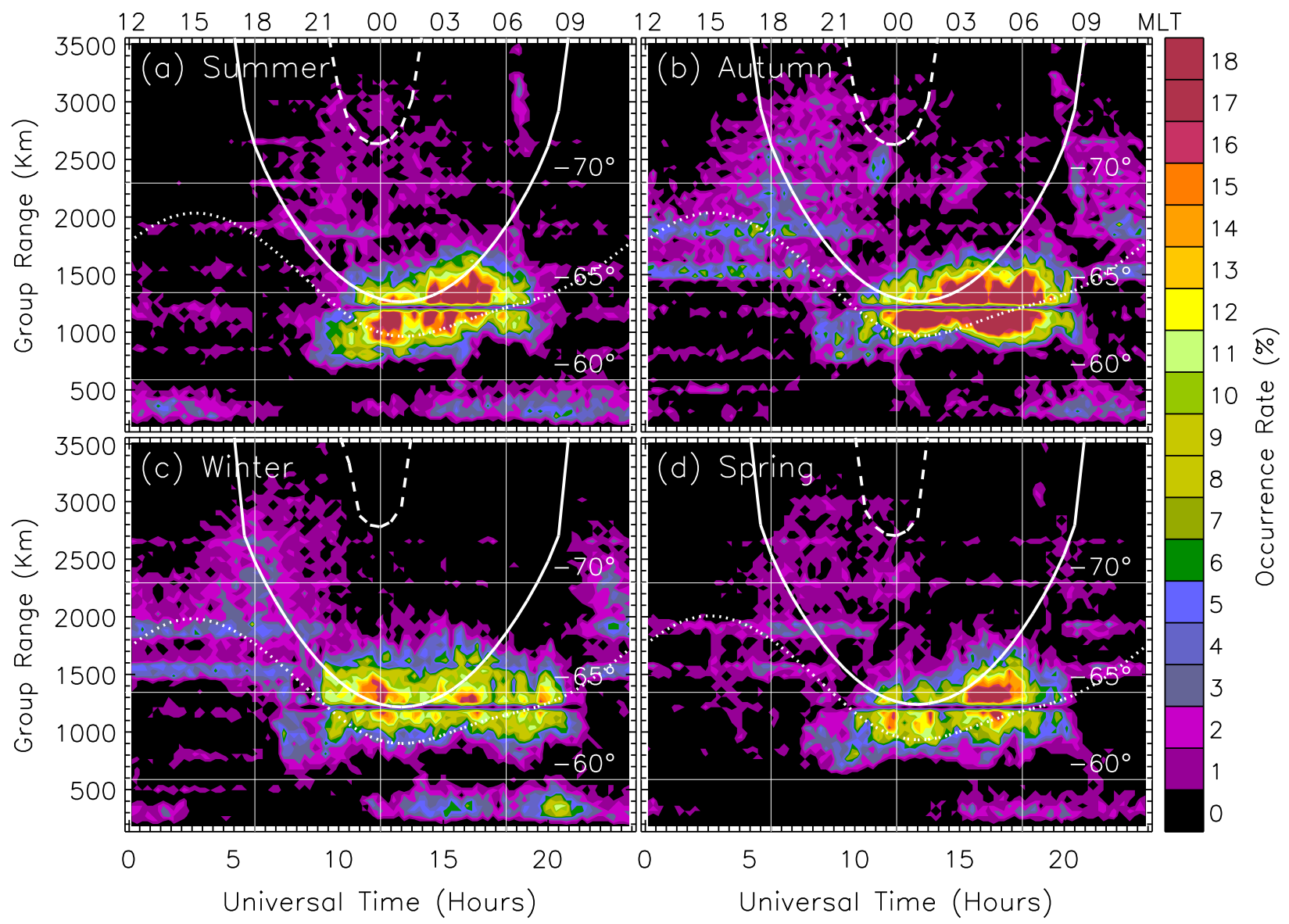

Fig. 10. The occurrence rate of population A echoes recorded on beam 15 during (a) summer, (b) autumn, (c) winter, and (d) spring for all $K_{p}$ values. The results are shown versus UT and group range, with magnetic latitudes $-60^{\circ},-65^{\circ}$, and $-70^{\circ} \Lambda$ superimposed. Nominal values of MLT in the ionosphere above Macquarie Island are given at top. Similar to Fig. 4, model auroral oval boundaries for (a) $A L=-109 \mathrm{nT}$ $\left(K_{p}=2.30\right)$, (b) $A L=-108 \mathrm{nT}\left(K_{p}=2.28\right)$, (c) $A L=-131 \mathrm{nT}\left(K_{p}=2.56\right)$, and (d) $A L=-120 \mathrm{nT}\left(K_{p}=2.43\right)$ have also been superimposed.

ture corresponds to the transition from westward to eastward return flows at the low-latitude limit of two-cell convection patterns, and is closely related to the Harang discontinuity, a feature normally identified using magnetometer data.

The colour coding used in Fig. 11 suggests large average westward flows were more extensive than large eastward flows. Indeed, some very large westward flows ( $>300 \mathrm{~m} \mathrm{~s}^{-1}$ ) overlapped the diffuse auroral oval, and extended equatorward into the sub-auroral ionosphere before magnetic midnight. For example, during summer there was an "island" of large westward flow centred near 21 MLT and $-62.5^{\circ} \Lambda$. Similar sub-auroral flows persisted during autumn and especially spring, but were concentrated at higher latitude during winter.

When sorted according to geomagnetic activity, the strong westward flows were absent at sub-auroral latitudes for $K_{p}=0$ to 1 . The auroral flows intensified with increasing $K_{p}$, becoming prevalent at sub-auroral latitudes for $K_{p}>3$ to 4 (and similarly for $B_{z}$ strongly negative). When only the echoes with spectral width $<38 \mathrm{~m} \mathrm{~s}^{-1}$ were considered, the region of large westward flow before midnight shifted equatorward into the sub-auroral ionosphere.

Note that beam 15 has a strong meridional component at latitudes equatorward of $-65^{\circ} \Lambda$. Hence, the large approaching velocities may have been due to the cross-polar jet. However, Fig. 7 shows that the cross-polar jet was usually extinguished in the 20 to 22 MLT sector equatorward of $-62.5^{\circ} \Lambda$. Thus, the large approaching velocities observed on beam 15 were indeed zonal and towards the west.

\section{Discussion}

\subsection{Beam 4 diurnal and $K_{p}$ variations}

From the auroral oval boundaries (Starkov, 1994b) superimposed in Fig. 4, we infer that most of the ionospheric echoes observed at ranges $>630 \mathrm{~km}$ on beam 4 were from decametre-scale irregularities drifting in the nightside discrete auroral and polar cap ionosphere. However, many echoes were from irregularities in the nightside diffuse au- 


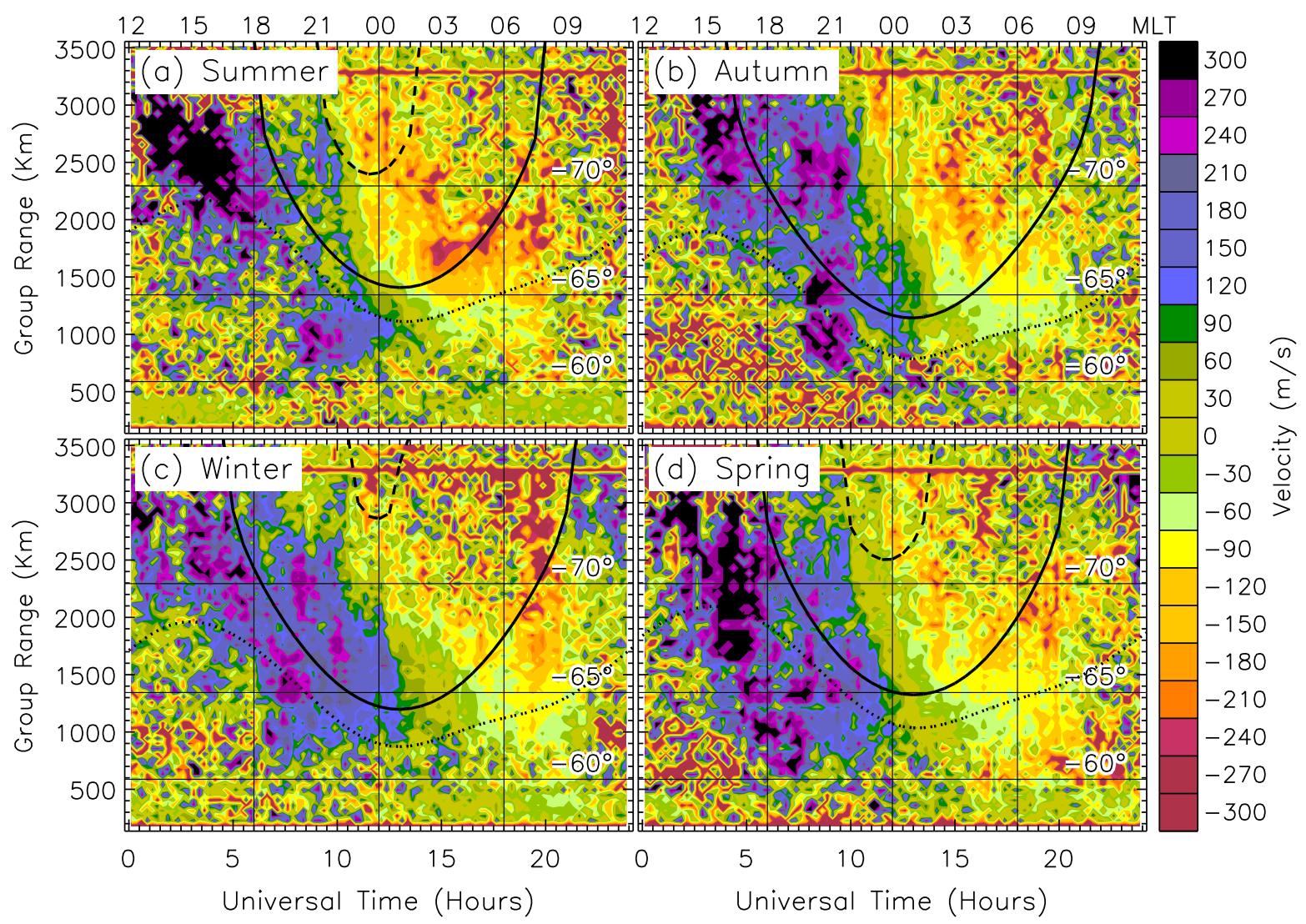

Fig. 11. Average LOS Doppler velocities for beam 15 ionospheric echoes with any spectral width and $K_{p}$ value recorded during (a) summer, (b) autumn, (c) winter, and (d) spring. The same model auroral oval boundaries used in Fig. 10 have been superimposed.

roral and sub-auroral ionosphere. There was also a tendency for large occurrence rates to shift pre-midnight for more disturbed conditions, $K_{p}>3(\mathrm{~d})$, (e), and (f). Figure 5 showed the location of the main band of nightside echoes tended to expand in longitude and equatorward with increasing levels of geomagnetic activity. For the quietest conditions, $K_{p}=0$ to 1 (Fig. 5a), most of the echoes were associated with the polar cap ionosphere, but for $K_{p}>2$ to 3 (Fig. 5c), and higher levels of activity, the majority of the echoes were associated with the expanded discrete auroral oval.

These results can be reconciled with the $K_{p}$ dependency observed for the Goose Bay radar in the Northern Hemisphere (Ruohoniemi and Greenwald, 1997). They found that the highest occurrence rates were observed in the nightside ionosphere for quiet conditions, and in the afternoon for disturbed conditions. This is because the Goose Bay radar is located $7.3^{\circ} \Lambda$ further poleward, and the main region of irregularity production expands equatorward of its FOV during disturbed conditions. They also argued that echoes were suppressed in the morning sector during disturbed conditions because of enhanced absorption due to energetic electron precipitation. The same effect occurs in the TIGER data, but it is weaker (Fig. 5d, e, and f), again probably because TIGER is located further equatorward of the auroral oval.

Figures 4, 5, and 10 show there was a tendency for more echoes to be observed post-midnight in the main band of auroral and polar cap echoes. The average backscatter power (Fig. 6) also maximised post-midnight, between 23 and 07 MLT, and was aligned with the leading edge of the main band of peak occurrence rate $\left(\sim-65^{\circ} \Lambda\right)$. Overall, more echoes were recorded with higher SNR post-midnight. What is the major cause of this feature in the observations?

A number of factors will affect the observation of ionospheric echoes with SuperDARN radars. They include the design and operation of the radar, changes in HF propagation conditions, and changes in the amplitude and number density of ionospheric irregularities. Changes in the operation of the radar cannot explain the occurrence of stronger echoes post-midnight because the radar was operated in the same way throughout the night. It is difficult to quantify the relative importance of changing propagation conditions without knowledge of the real ionospheric conditions combined with ray tracing. However, the $f_{\text {min }}$ variations in ionograms recorded at high mid-latitude stations show that absorption due to insolation tends to decrease at sunset, and not near midnight. Moreover, D-region absorption due to electron precipitation increases post-midnight. Thus, it seems reasonable to speculate that stronger echoes were observed post-midnight, largely because of more intense irregularity formation. 
Tsunoda (1988) provided a possible explanation for why stronger irregularities should be observed post-midnight. The linear growth rate for the $\boldsymbol{E} \times \boldsymbol{B}$ instability (Linson and Workman, 1970) is $\gamma_{0}=V_{0} / L$ for $\omega \ll v_{i n}$, where $V_{0}$ is the "slip" velocity, or the magnitude of the plasma velocity minus the neutral wind velocity. $L$ is the gradient scale length of plasma density, $\omega=\omega_{r}+j \gamma_{0}$ is the wave frequency, and $v_{i n}$ is the ion-neutral collision frequency. Tsunoda (1988) explains how gradient drift waves should grow in proportion to the slip velocity, since if $V_{0}=0$, no Pedersen currents can flow to provide the polarisation fields which destabilise the plasma density. Larger growth rates might lead to the formation of more intense irregularities, but this is still a point of conjecture.

Figures 29, 30, and 31 reproduced in Tsunoda (1988) suggest that larger slip velocities occur post-midnight, supporting his prediction that stronger irregularity production should occur post-midnight. Conde and Innis (2001) recently reported more thermospheric gravity-wave perturbations occur post-midnight, also implying greater slip velocities. Parkinson et al. (2002b) presented a case study (see their Fig. 3) which showed sudden increases in backscatter power in association with velocity transients occurring past the Harang discontinuity. The backscatter power also tended to increase in proximity to the poleward boundary of the auroral oval.

Note that larger slip velocities should tend to occur whenever ionospheric electric fields or neutral winds change rapidly, since it takes some time for an equilibrium to be achieved between the ion and neutral gas motions. Moreover, larger slip velocities should also tend to occur wherever the ionospheric electric fields vary rapidly in a spatial sense, such as near the poleward boundary of the auroral oval (see Tsunoda, 1988). Thus, strong ionospheric echoes might be observed by SuperDARN radars, even during periods of steady-state convection. A statistical analysis of echo occurrence sorted according to spatial and temporal variability in the ionospheric convection may help to address these issues.

Because of the short lifetime of decametre irregularities, Fig. 4 of this paper suggests that the most active source region for the irregularities observed using TIGER was the nightside ionosphere overlapping the poleward edge of the auroral oval, and extending into the discrete auroral oval. Figure 5 suggests that this source region tended to shift equatorward and pre-midnight into the discrete auroral oval during more disturbed intervals. Although the post-midnight echoes may have been partly suppressed by enhanced absorption (Ruohoniemi and Greenwald, 1997), we speculate that the trend was also caused by more slip-velocity transients developing pre-midnight because of ionospheric substorms.

Although the average occurrence rates (Table 2) for the largest $K_{p}$ values were only representative of a small number of storms, they clearly showed that localised "hot spots" of echo occurrence were often observed, even during major storms when there was intense particle precipitation. Ionospheric absorption due to particle precipitation reduced the echo occurrence in transient, spatially localised episodes.
However, overall, the echo occurrence remained very high during major storms, perhaps because of strong and frequent slip-velocity transients.

\subsection{Beam 4 propagation effects}

Figure 4 showed that the enhanced echo occurrence actually consisted of two separate regions, a main one found between $\sim-65^{\circ} \Lambda$ and $-76^{\circ} \Lambda$ and persisting beyond magnetic midnight, and a lesser patch of mostly polar cap echoes observed between $\sim-70^{\circ} \Lambda$ and $-82^{\circ} \Lambda$ near dusk. The familiar equatorward expansion of the auroral oval with MLT (for the same level of geomagnetic activity) can only partly explain these two echo regions. This is because one of them clearly lay well into the polar cap.

Recall that variability in the refraction of the radio waves influences the observation of ionospheric echoes. The ionospheric electron density encountered along the ray path determines the preferred range windows at which the radio waves achieve normal incidence with magnetically field-aligned irregularities (Villain et al., 1985). To produce observable echoes, these preferred range windows must also correspond to ionospheric regions associated with intense irregularity production.

However, the location of the preferred range windows is variable, and to some extent decametre irregularities will be observed wherever they occur. This is because they form as a part of a cascade process: $10-\mathrm{m}$ scale irregularities form on the gradients of $100-\mathrm{m}$ scale irregularities, which form on the gradients of 1-km scale irregularities, etc. Hence, the 10-m scale irregularities will often form in the presence of largescale gradients required to refract the radio waves to normal incidence.

The lesser patch of mostly polar cap echoes observed at higher latitude on the dusk side corresponds to a preferred range window due to 1.5-hop propagation, and the main band of echoes observed at lower latitude and later MLT corresponds to a preferred range window due to 0.5 -hop propagation. In a statistical sense, these two preferred range windows overlap. However, the lesser region of mostly polar cap echoes tended to occur during quiet conditions because the main auroral oval expanded equatorward into the preferred range window due to 0.5 -hop propagation during more disturbed conditions. Presumably, echoes were usually not observed at dusk via 0.5 -hop propagation during quiet conditions because of weak irregularity production in the subauroral ionosphere where insolation was more direct.

The preceding interpretation was confirmed by (i) the similar effects observed at similar group ranges on beam 15 , (ii) the sudden decrease in operating frequency at 19 MLT (Fig. 3) which subsequently favoured observation of echoes via 0.5 -hop propagation, (iii) elevation angle data (not shown) which suggested that the two echo regions were observed via different propagation modes, and (iv) examination of the behaviour of 1.5-hop ionospheric echo traces with respect to 1.0-hop sea-echo traces in range-time plots for individual days. 
The behaviour of the sea-echo traces was consistent with the behaviour of the ionospheric parameters $h m \mathrm{~F} 2$ and $f o \mathrm{~F} 2$ in ionograms recorded nearby TIGER at Hobart $\left(147.3^{\circ} \mathrm{E}\right.$, $42.9^{\circ} \mathrm{S}$ geographic). Past sunset, $h m \mathrm{~F} 2$ increased and $f o \mathrm{~F} 2$ decreased, and 1.0-hop sea-echo traces gradually receded to great ranges until they were lost. Ionospheric echoes in the preferred range window due to 1.5 -hop propagation were observed until this happened. Then nightside auroral E- and Flayers began to support the observation of echoes via 0.5 -hop propagation.

\subsection{Beam 4 seasonal variations}

Some of the echoes observed using TIGER were associated with the pre-noon greater cusp, consisting of the true cusp, cleft, and mantle (Newell and Meng, 1992). For example, there was a peak occurrence rate of $\sim 46 \%$ near 08:40 MLT and $-78^{\circ} \Lambda$ during winter (Fig. $4 \mathrm{c}$ ). This feature was centred poleward of the poleward edge of the auroral oval, so many of the corresponding irregularities may have been concentrated in the mantle rather than the cusp proper. Why were so few dayside echoes observed, especially when the cusp is known to be such an intense source of irregularity production?

The true ranges of the auroral and polar cap ionosphere were greater during the daytime. Except during very disturbed conditions, dayside echoes were probably observed via 1.5- and 2.5-hop propagation, resulting in greater divergent power losses. D-region absorption due to insolation was also probably greatest during the daytime (cf. Fig. 6), just past noon $(\sim 13 \mathrm{MLT})$ in summer, when the Sun was high in the sky, and least during the early morning in the winter when the Sun was beneath the horizon. However, Ruohoniemi and Greenwald (1997) argued that suppression of large-scale plasma density gradients during the summer was the main cause of a similar wintertime maximum in dayside cusp echoes observed in the Northern Hemisphere.

The contraction of the lesser region of mostly polar cap echoes from dusk in winter toward later MLT in summer (Fig. 4; Sect. 3.1.1) is consistent with the well-known seasonal variation in F-region sunset time. The location of the terminator is a very important consideration because decades of ionosonde measurements have shown that the ionosphere is smoother when directly illuminated. There is a sound theoretical basis for these observations. First, the large-scale gradients in plasma density required for production of smaller scale irregularities are suppressed by insolation. Second, the presence of a conducting E region reduces the lifetime of irregularities in the F-region by allowing the cross-field plasma diffusion to proceed at the faster ion rate, rather than the slower electron rate (Vickrey and Kelley, 1982; Kelley et al., 1982). Hence, all else being equal, irregularities "dissolve" faster in the presence of a conducting E-region.

Table 2 showed the average occurrence rate of ionospheric echoes at ranges $>630 \mathrm{~km}$ was greatest during autumn $(18.7 \%)$, then winter $(15.6 \%)$, spring $(15.0 \%)$, and least of all during summer (13.7\%). The variation of beam 15 echoes was similar and largely determined by variations in the oc- currence of irregularities in the nightside auroral oval. Although relatively small, the variations were statistically significant and similar to the familiar, but unexplained, seasonal variation in auroral activity, with peak activity near the March (austral autumn) equinox. We note that if reliable $A L$ indices were available for our study period, they might have shown peak auroral activity, and thus irregularity production, near the March equinox.

Scintillation of VHF signals traversing the ionosphere and received with ground-based antennas are caused by ionospheric irregularities of scale size $\sim 250 \mathrm{~m}$ to $1 \mathrm{~km}$. Typical power spectra of ionospheric irregularities show a cascade of irregularities from these scale sizes down to the decametrescale size observed using HF backscatter radar (Tsunoda, 1988). Hence, we expect there to be a correspondence between the occurrence of ionospheric irregularities implied by the two measurement techniques.

Indeed, the diurnal and seasonal variation of scintillation index observed at Narssarssuaq, Greenland $\left(+63^{\circ} \Lambda\right)$ (Aarons, 1982), (see Fig. 19 therein) resembled the variation of occurrence rate shown in Table 2. The Narssarssuaq scintillation index maximised in the months of March and April, and then slowly declined throughout the remainder of the year, reaching a minimum during November and December. A similar but weaker seasonal behaviour was observed using TIGER, even though the stations reside in different longitude sectors, and opposite hemispheres. The diurnal maxima also had similar character. However, the diurnal scintillation maxima were centred pre-midnight $(\sim 23 \mathrm{MLT})$ at Narssarssuaq, whereas the diurnal maxima of TIGER echoes tended to occur post-midnight.

Basu (1975) investigated the UT seasonal variations of auroral zone activity by compiling average $A L$ indices. Basu's analysis revealed variations in auroral activity which were attributed to variations in the plane of symmetry of the plasma sheet with respect to the solar magnetospheric equatorial plane. The seasonal variations in $A L$ were consistent with the seasonal variation in Narssarssuaq scintillations. The seasonal variations were strongest for auroral stations in the geographic meridian containing, or opposite to, the geomagnetic pole. It is likely $A L$ is also a measure of decametre irregularity production, as well as scintillation activity. Consulting Fig. 2 of Basu (1975), there should be a relatively weak seasonal variation in echo occurrence observed at a station where magnetic midnight occurs at $\sim$ 14:00 UT. This is consistent with the relatively weak seasonal variation of TIGER echoes.

It is well known that changes in the dipole tilt angle regulate the transfer of solar-wind energy into the coupled magnetosphere-ionosphere-thermosphere system (Russell and McPherron, 1973). However, the system is very complex and many factors must be considered to explain the peak irregularity production near autumn equinox. These factors include variations in conditions satisfying the antiparallel merging hypothesis (Crooker, 1979), and variations in the ionospheric conductivity due to changes in the solarzenith angle and particle precipitation. The conductivity of 
the conjugate ionosphere will also affect the closure of fieldaligned currents. Aurora, intense electric fields, and thus irregularity production concentrate in regions of low ionospheric conductivity (Newell et al., 2001).

In this section we outlined two different kinds of seasonal variation in irregularity occurrence. Earlier we discussed the direct role of insolation in producing D-region absorption, and concentrating the regions of strong irregularity production in the nightside ionosphere. This kind of seasonal variation is asymmetric across hemispheres, that is, the region of strongest irregularity production is greatest in the winter hemisphere. Then we discussed the familiar variation in auroral activity which maximises in the austral autumn (boreal spring). This contribution is symmetric across hemispheres. Both the asymmetric and symmetric contributions help to explain the seasonal variations revealed in Fig. 4.

\subsection{Beam 4 LOS Doppler velocities and spectral widths}

Figure 7 showed the average LOS Doppler velocities sorted according to the IMF vector, with DICM equipotentials superimposed to help show how the radar observations were consistent with a basic two-cell convection pattern with a cross polar cap jet most developed under $B_{z}$ negative conditions. Further detail can be compared; for example, Fig. 7c shows a region of near zero LOS velocity (karki) centred near $\sim 04$ MLT and $-75^{\circ} \Lambda$. This implies the location of the centre of the dawn convection cell, in better agreement with the results of the DICM model than the DMSP-calibrated IZMEM model (Papitashvili and Rich, 2002; see their Figs. 2 and 7). However, such comparisons are best made using SuperDARN convection potentials derived using LOS Doppler velocities measured by all the SuperDARN radars combined (Shepherd and Ruohoniemi et al., 2000).

When average Doppler parameters were sorted according to season (not shown) they revealed that the region of large poleward velocities and spectral widths centred in the prenoon ionosphere were more extensive during summer, then spring, winter, and least of all during autumn. This is nearly opposite to the seasonal variation in echo occurrence in the pre-noon ionosphere, namely a maximum during winter, then autumn, spring, and least of all during summer. To first order, one might expect the echo occurrence (and average spectral widths) to increase with convection velocity. However, a deeper analysis of the conditions affecting the growth and decay of irregularities is required. This includes determining the slip velocities, and allowing for enhanced conductivity due to direct insolation which maximises in summer.

Figure 8 showed the average Doppler velocity spectral widths for all seasons and $K_{p}$ values combined. Variations in the spectral widths may represent genuine variations in the hydromagnetic wave activity (André et al., 1999, 2000a, 2000b) or small- to medium-scale turbulence in the plasma convection. The region of large spectral widths extended into the pre-noon ionosphere and intensified with increasing $K_{p}$ (or $B_{z}$ southward) conditions (not shown). This suggests dayside reconnection may have driven the hydromagnetic wave activity or turbulence responsible for the large spectral widths.

André et al. (2000b) also showed how large-scale gradients and especially strong flow shears in the plasma convection will enhance the spectral widths. However, the average spectral widths shown in Fig. 8 were observed on the meridional beam 4 which was never parallel to the normal dawn or dusk convection reversal boundary (CRB). Nevertheless, strong flow shears must have occurred throughout the study interval, and may explain some of the larger spectral widths affecting the statistics.

Well-known ionospheric locations mapping to the greater cusp, polar cap (PC), and CRB were superimposed in Fig. 8. When the spectral widths are plotted versus group range and time for TIGER beam 4, a persistent latitudinal decrease in nightside spectral width is often observed (Parkinson et al., $2002 b$ ). The spectral width boundary is usually very sharp, occurring within two range gates or $\sim 90 \mathrm{~km}$, and its location expands equatorward or contracts poleward, depending on geomagnetic activity. The nightside spectral widths decreased gradually in Fig. 8, because they were averaged over the non-stationary behaviour of the spectral width boundary revealed in case studies. Nevertheless, the gradual statistical boundary still expanded equatorward with $K_{p}$.

Parkinson et al. (2002b) also argued that (i) the spectral width boundary mapped to the open-closed magnetic field line boundary (OCB) in the evening and midnight sector, (ii) the scatter with low spectral width just equatorward of the spectral width boundary mapped to the auroral oval, and (iii) the equatorward limit of this scatter mapped to the poleward wall of the main ionospheric trough. Hence, we have inferred nominal locations of the OCB, plasma sheet boundary layer (PSBL), central plasma sheet (CPS), and plasmapause in Fig. 8. For example, we have placed the plasmapause near $L=4$.

Note that because the spectral width boundary is so sharp in case study data, it is well defined using any spectral width threshold between $\sim 50$ and $200 \mathrm{~m} \mathrm{~s}^{-1}$. However, Fig. 9 suggests that the use of a lower (higher) threshold will more exclusively select population A (B) echoes only.

Large spectral widths were observed encircling the dawn sector but not the dusk sector. This suggests that there may be more hydromagnetic wave activity or turbulence in the dawn sector. The bite out in large spectral widths centred on dusk may be related to the dusk bulge of the plasmapause which disappears during geomagnetic storms, or large $K_{p}$, as was observed.

Lastly, we speculate that the thin band of large spectral widths $>200 \mathrm{~m} \mathrm{~s}^{-1}$ found between 02:30 to 07:30 MLT and $-60^{\circ} \Lambda$ and $-63^{\circ} \Lambda$ may be associated with strong F-region irregularities forming high in the pre-sunrise trough when electron densities plummet.

\subsection{Beam 15 results}

Figure 9 revealed two separate populations of ionospheric echoes, "A" and "B", having low and moderate to very 
large spectral widths, respectively. Parkinson et al. (2002b) showed that population A (B) tended to occur equatorward (poleward) of the OCB in the pre-midnight sector, but the morphology of the two populations was complicated. For example, echoes with large spectral width occurred equatorward of the OCB, and vice versa. No doubt other populations exist. Nevertheless, the existence of two populations, one mapping to closed field lines and the other to open field lines, must be indicative of the magnetospheric processes driving the velocity fluctuations causing the large spectral widths.

The peak occurrence rate occurred at the mode value $\sim 9 \mathrm{~m} \mathrm{~s}^{-1}$ for beam 15 , but at the mode value $\sim 70 \mathrm{~m} \mathrm{~s}^{-1}$ for beam 4. This is largely due to a simple geometrical effect: beam 15 samples many more ranges in the sub-auroral and auroral ionosphere where the echoes with low spectral widths are concentrated. Moreover, beam 15 becomes a magnetic zonal beam, and thus is more sensitive to intense irregularities growing in the direction of the primary $\boldsymbol{E} \times \boldsymbol{B}$ waves which must drift zonally at lower latitudes.

On the other hand, irrespective of spectral width and range, more echoes were observed on beam 4 than beam 15 (1 666429 versus 1357305 ). This is because beam 4 is a meridional beam which traverses a greater range of latitudes, thereby increasing the probability of encountering conditions favouring the formation of ionospheric irregularities. Beam 4 is also more sensitive to the intense, primary $\boldsymbol{E} \times \boldsymbol{B}$ waves drifting in the direction of the cross-polar cap jet.

Figure 10 showed that the peak occurrence rates of population A echoes on beam 15 were displaced further toward dawn and equatorward than for beam 4 . This is because strong equatorward flows in the cross-polar jet tend to occur pre-midnight, and favour production of population $\mathrm{B}$ echoes, whereas strong eastward return flows tend to occur post-midnight, favouring production of population A echoes. Perhaps the strong westward flows tending to occur premidnight are less effective at generating irregularities because of the smaller slip velocities (Tsunoda, 1988).

Population A echoes observed using the TIGER radar are reminiscent of the "dusk scatter" first reported by Ruohoniemi et al. (1988) using observations made with the Goose Bay radar $\left(60.45^{\circ} \mathrm{W}, 53.3^{\circ} \mathrm{N}\right.$ geographic; $\left.+61.9^{\circ} \Lambda\right)$. The occurrence of dusk scatter maximises in the main ionospheric trough near the solar terminator during the winter (Hosokawa et al., 2002). TIGER beam 15 observations during the winter revealed the lesser patch of mostly auroral oval echoes detected via 1.5-hop propagation (Fig. 10c). Similar to dusk scatter, these echoes had peak occurrence rates in the diffuse auroral oval at $\sim 18$ MLT. However, for TIGER, the dusk scatter did not stand out as a separate or dominant feature in the sub-auroral ionosphere. Rather, the dominant feature for this kind of scatter was centred in the post-midnight diffuse auroral oval.

During the winter TIGER detects population A echoes at dusk via 1.5-hop propagation between $\sim 15$ and 22 MLT and $-65^{\circ} \Lambda$ and $-72^{\circ} \Lambda$. Because the Goose Bay radar is located at higher latitude $\left(+61.9^{\circ} \Lambda\right.$ vs. $\left.-54.6^{\circ} \Lambda\right)$, it will observe the same kind of irregularities via 0.5 -hop propagation. How- ever, it will become more difficult for the Goose Bay radar to observe population A echoes at later MLT when the diffuse auroral oval expands equatorward. On the other hand, the TIGER radar will observe the diffuse auroral oval via 0.5 hop propagation, even at magnetic midnight. However, this does not preclude the possibility of "hot spots" in the occurrence of population A echoes measured by other radars, such as where the solar terminator crosses the main ionospheric trough, or in the aftermath of SAIDs (Parkinson et al., 2003).

Furthermore, because of the tilt of the geomagnetic dipole toward Australia, the TIGER radar is only $7.3^{\circ}$ magnetically equatorward of the Goose Bay radar, yet $9.9^{\circ}$ geographically equatorward. During the winter the sunset terminator crosses the Goose Bay field-of-view (FOV) at a significantly earlier MLT than the TIGER FOV. This may explain why dusk scatter is detected via 0.5-hop propagation using the Goose Bay radar but not TIGER. Direct insolation of the 0.5 -hop range window for TIGER will cause the dissipation of ionospheric irregularities. Annual variations in the location of the sunset terminator are also consistent with seasonal variations in beam 15 observations.

Finally, beam 15 is very sensitive to SAIDs, which occur pre-midnight in regions of low ionospheric conductivity such as the main ionospheric trough (Anderson et al., 1991). The observed seasonal variation in large westward flows, Fig. 11, must be related to the insolation and thus conductivity of the radar FOV and its conjugate location, as well as the occurrence of substorms leading to the formation of SAIDs. The $K_{p}$ and spectral width dependency of the westward flows also supports an association between substorms, SAIDs, and the formation of the main ionospheric trough (Parkinson et al., 2003).

\section{Summary}

In this paper we compiled occurrence statistics for ionospheric echoes observed using the TIGER radar $\left(-54.6^{\circ} \Lambda\right)$ on the magnetic meridian or "polar cap" beam 4 , and the magnetic zonal or "auroral" beam 15. These two beams are nearly orthogonal and summarise most of the important aspects of ionospheric echoes observed using the radar:

1. Two populations of ionospheric echoes were identified. Population A echoes had low spectral width and a mode value of $\sim 9 \mathrm{~m} \mathrm{~s}^{-1}$ (bin size of $2 \mathrm{~m} \mathrm{~s}^{-1}$ ), and were concentrated in the nightside auroral ionosphere. Population $\mathrm{B}$ echoes had high spectral width and a mode value of $\sim 70 \mathrm{~m} \mathrm{~s}^{-1}$, and were concentrated in the polar cap ionosphere. More population A echoes were observed using beam 15 , with peak occurrence rates overlapping the average location of the nightside diffuse auroral oval. On the other hand, more population $\mathrm{B}$ echoes were observed on beam 4 , with peak occurrence rates overlapping the average location of the discrete auroral oval and polar cap ionosphere. 
2. Populations A and B must exist because of distinct dynamical regions in the coupled magnetosphereionosphere system. For example, population A echoes were concentrated on closed field lines between dusk and dawn, whereas population B echoes were concentrated on open field lines (Parkinson et al., 2002b). The larger spectral widths of population B may be caused by enhanced hydromagnetic wave activity transmitted to the polar cap ionosphere (e.g. some nightside variant of the André et al., 1999 hypothesis), or more turbulent plasma flow within the polar cap ionosphere.

3. There was a dusk "bite out" of large spectral widths between $\sim 15$ and 21 MLT and poleward of $-67^{\circ} \Lambda$. This feature may be related to the dusk bulge of the plasmapause, and is consistent with an enhancement of population A echoes in the dusk sector. Other poorly understood features include the pre-dawn enhancement of a large spectral width located between $\sim 03$ and 07 MLT, and centred on $\sim-61^{\circ} \Lambda$. Because this feature maps to near the expected location of the main ionospheric trough ( $L \sim 4$ to 5 ), it may be caused by patches of fieldaligned irregularities sometimes observed within or near the pre-sunrise trough (Parkinson et al., 1996).

4. The main source region for the nightside irregularities observed by TIGER included the discrete auroral oval and polar cap ionosphere just poleward of the OCB. Peak occurrence rates of beam 4 echoes were often $>60 \%$ just after magnetic midnight and $\sim-70^{\circ} \Lambda$. They tended to shift pre-midnight and equatorward with increasing $K_{p}\left(B_{z}\right.$ southward $)$ due to expansion of the auroral oval and substorm activity. Overall, more echoes with higher SNR were observed post-midnight, perhaps because of larger slip velocities there, consistent with a basic prediction of $\boldsymbol{E} \times \boldsymbol{B}$ instability theory (Tsunoda, 1988).

5. Peak occurrence rates remained high even for $K_{p}>$ 4 , despite enhanced D-region absorption due to particle precipitation. This suggests the more poleward SuperDARN radars fail to observe many echoes during storms, largely because the ionospheric irregularities expand equatorward of their FOVs. Moreover, the radio-wave paths for TIGER may refract into the F-region without traversing regions of strong absorption, whereas this is less likely to occur for the Northern Hemisphere radars located under the auroral oval.

6. Nightside echoes were typically observed first via 1.5hop propagation near dusk and then via 0.5-hop propagation during pre-midnight to dawn. Variations in the transition time between the two modes was earliest during winter ( $\sim 20 \mathrm{MLT})$, and latest during summer ( $\sim 23$ MLT), consistent with the familiar seasonal variation in the F-region terminator.

7. The subset of population A echoes observed on beam 15 near dusk had characteristics reminiscent of dusk scat- ter (Ruohoniemi et al., 1988), but population A echoes were not a distinct feature confined to the sub-auroral ionosphere, and their occurrence maximised postmidnight because of TIGER's lower latitude.

8. The seasonal variation in echo occurrence was relatively weak, but showed a familiar peak in auroral activity near the March (austral autumn) equinox. This relatively weak variation was consistent with the known longitudinal variations in auroral zone magnetic activity (Basu, 1975).

9. Figure 11, the average LOS Doppler velocities on the zonal beam 15, suggest that SAID-like phenomena occurred frequently in the sub-auroral and auroral ionosphere, especially in the pre-midnight sector.

We conclude that the TIGER radar can be used to study nightside ionospheric irregularities during all seasons and under a broad range of geomagnetic conditions. Knowledge of these occurrence statistics will facilitate the design of numerous experiments, and the subsequent interpretation of results, and thus further improve our understanding of some of the features shown here.

Acknowledgements. This work was supported by the Australian Research Council, the Australian Antarctic Science Advisory Council, and the Ian Potter Foundation. We thank N. F. Ness of the Bartol Research Institute for making ACE magnetic field data available over the internet, and Vladimir Papitashvili for providing us with the source code for the DICM convection model. We also thank the numerous people who contributed to the construction, development, and maintenance of TIGER.

Topical Editor M. Lester thanks M. Ruohoniemi and another referee for their help in evaluating this paper.

\section{References}

Aarons, J.: Global morphology of ionospheric scintillations, Proc. IEEE, 70, 359-378, 1982.

Anderson, P. C., Heelis, R. A., and Hanson, W. B.: The ionospheric signatures of rapid subauroral ion drifts, J. Geophys. Res., 96, 5785-5792, 1991.

André, R., Pinnock, M., and Rodger, A. S.: On the SuperDARN autocorrelation function observed in the ionospheric cusp, Geophys. Res. Lett., 26, 3353-3356, 1999.

André, R., Pinnock, M., and Rodger, A. S.: Identification of the low-altitude cusp by Super Dual Auroral Radar Network radars: A physical explanation for the empirically derived signature, J. Geophys. Res., 105, 27 081-27 093, 2000a.

André, R., Pinnock, M., Villain, J.-P., and Hanuise, C.: On the factors conditioning the Doppler spectral width determined from SuperDARN HF radars, Int. J. Geomag. Aeronomy, 2, 77-86, $2000 b$.

Baker, K. B. and Wing, S.: A new magnetic coordinate system for conjugate studies of high latitudes, J. Geophys. Res., 94, 91399143, 1989.

Baker, K. B., Dudeney, J. R., Greenwald, R. A., et. al.: HF radar signatures of the cusp and low-latitude boundary layer, J. Geophys. Res., 100, 7671-7695, 1995. 
Basu, S.: Universal time seasonal variation of auroral zone magnetic activity and VHF scintillation, J. Geophys. Res., 80, 4725, 1975.

Conde, M. and Innis, J.: Thermospheric vertical wind activity mapped by the Dynamics Explorer-2 satellite, The Cedar Post, 43, 12 September, 2001.

Crooker, N. U.: Dayside merging and cusp geometry, J. Geophys. Res., 84, 951-959, 1979.

Davies, K.: Ionospheric Radio, IEE Electromagnetic Waves Series 31, London, UK: Peter Peregrinus Ltd., 1990.

Davis, T. N. and Sugiura, M.: Auroral electrojet activity index AE and its universal time variations, J. Geophys. Res., 71, 785, 1966.

Dyson, P. L. and Devlin, J. C.: The Tasman International Geospace Environment Radar, The Physicist (The Australian Institute of Physics), 37, 48-53, March/April, 2000.

Fejer, B. G. and Kelley, M. C.: Ionospheric irregularities, Rev. Geophys. Space Phys., 18, 401-454, 1980.

Fukumoto, M., Nishitani, N., Ogawa, T., Sato, N., Yamagishi, H., and Yukimatu, A. S.: Statistical analysis of echo power, Doppler velocity and spectral width obtained with the Syowa south HF radar, Adv. Polar Upper Atmos. Res., 13, 37-47, 1999.

Galperin, Y. I., Ponomarev, V. N., and Zosimova, A. G.: Direct measurements of ion drift velocity in the upper ionosphere during a magnetic storm, 2. Results of measurements during the November 3, 1967, magnetic storm, Cosmic Res. (Russian), 11, 283292,1973

Greenwald, R. A., Baker, K. B., Hutchins, R. A., and Hanuise, C.: An HF phased-array radar for studying small-scale structure in the high-latitude ionosphere, Radio Sci., 20, 63-79, 1985.

Greenwald, R. A., Baker, K. B., Dudeney, J. R., et. al.: DARN/SuperDARN: A global view of the dynamics of highlatitude convection, Space Sci. Rev., 71, 761-796, 1995.

Gussenhoven, M. S., Hardy, D. A., and Heinemann, N.: Systematics of the equatorward diffuse auroral boundary, J. Geophys. Res., 88, 5692-5708, 1983.

Hall, G. E., MacDougall, J. W., Moorcroft, D. R., St.-Maurice, J.P., Manson, A. H., and Meek, C. E.: Super Dual Auroral Radar Network observations of meteor echoes, J. Geophys. Res., 102, 14 603-14 614, 1997.

Hanuise, C., Villain, J. P., Cerisier, J. C., Senior, C., Ruohoniemi, J. M., Greenwald, R. A., and Baker, K. B.: Statistical study of high-latitude E-region Doppler spectra obtained with the SHERPA HF radar, Ann. Geophysicae, 9, 273-285, 1991.

Hanuise, C., Villain, J. P., Gresillon, D., Cabrit, B., Greenwald, R. A., and Baker, K. B.: Interpretation of HF radar ionospheric Doppler spectra by collective wave scattering theory, Ann. Geophysicae, 11, 29-39, 1993.

Hosokawa, K., Iyemori, T., Yukimatu, A. S., and Sato, N.: Spatial distribution of irregularity occurrence rate in the subauroral Fregion as observed by the SuperDARN radars, Proc. SuperDARN 2000 Workshop, Beechworth, Australia., 2000.

Hosokawa, K., Sugino, M., Lester, M., Sato, N., Yukimatu, A. S., and Iyemori, T.: Simultaneous measurement of duskside subauroral irregularities from the CUTLASS Finland radar and EISCAT UHF system, submitted to J. Geophys. Res., 2002.

Jayachandran, P. T., St.-Maurice, J.-P., MacDougall, J. W., and Moorcroft, D. R.: HF Detection of slow long-lived E-region plasma structures, J. Geophys. Res., 105, 2425-2442, 2000.

Jenkins, B., Jarvis, M. J., and Forbes, D. M.: Mesospheric wind observations derived from Super Dual Auroral radar network (SuperDARN) HF radar meteor echoes at Halley, Antarctica: Preliminary results, Radio Sci., 33, 957-965, 1998.
Kelley, M. C., Vickrey, J. F., Carlson, C. W., and Torbert, R.: On the origin and spatial extent of high-latitude F-region irregularities, J. Geophys. Res., 87, 4469-4475, 1982.

Kelley, M. C.: The Earth's ionosphere - Plasma physics and electrodynamics, Academic Press, San Diego, California, 1989.

Kivelson, M. G. and Russell, C. T. (Eds): Introduction to space physics, Cambridge Univ. Press, Cambridge, U.K., 1995.

Leonard, J. M., Pinnock, M., Rodger, A. S., Dudeney, J. R., Greenwald, R. A., and Baker, K. B.: Ionospheric plasma convection in the southern hemisphere, J. Atmos. Solar-Terr. Phys., 57, 889897, 1995.

Lester, M., Milan, S. E., Besser, V., and Smith, R.: A case study of $\mathrm{HF}$ radar spectra and $630.0 \mathrm{~nm}$ auroral emission in the premidnight sector, Ann. Geophysicae, 19, 327-339, 2001.

Lewis, R. V., Freeman, M. P., Rodger, A. S., Reeves, G. D., and Milling, D. K.: The electric field response to the growth phase and expansion phase onset of a small isolated substorm, Ann. Geophysicae, 15, 289-299, 1997.

Linson, L. M. and Workman, J. B.: Formation of striations in ionospheric plasma clouds, J. Geophys. Res., 75, 3211, 1970.

Lui, A. T. Y.: Current controversies in magnetospheric physics, Reviews Geophys., 39, 535-563, 2001.

Milan, S. E., Jones, T. B., Robinson, T. R., Thomas, E. C., and Yeoman, T. K.: Interferometric evidence for the observation of ground backscatter originating behind the CUTLASS coherent HF radars, Ann. Geophysicae, 15, 29-39, 1997a.

Milan, S. E., Yeoman, T. K., Lester, M., Thomas, E. C., and Jones, T. B.: Initial backscatter occurrence statistics from the CUTLASS HF radars, Ann. Geophysicae, 15, 703-718, $1997 \mathrm{~b}$.

Newell, P. T. and Meng, C.-I.: Mapping the dayside ionosphere to the magnetosphere according to particle precipitation characteristics, Geophys. Res. Lett., 19, 609-612, 1992.

Newell, P. T., Greenwald, R. A., and Ruohoniemi, J. M.: The role of the ionosphere in aurora and space weather, Rev. Geophys., 39, 137-149, 2001.

Nishitani, N., Ogawa, T., Sato, N., Yamagishi, H., Yukimatu, A. S., and Watanabe, M.: Averaged pattern of ionospheric echo region and convection: initial results from the Syowa station HF radar, Proc. NIPR Symp. Upper Atmos. Phys., 10, 42-49, 1997.

Papitashvili, V. O. and Rich, F. J.: High-latitude ionospheric convection models derived from Defense Meteorological Satellite Program ion drift observations and parameterized by the interplanetary magnetic field strength and direction, J. Geophys. Res., 107, in Press, 2002.

Parkinson, M. L., Dyson, P. L., and Quach, A. T. D.: Arrival of ionospheric troughs and oblique spread-F in the wake of largescale travelling ionospheric disturbances during the intense auroral storms of August 22 and 23, 1990, J. Geomag. Geoelect., 48, 1381-1405, 1996.

Parkinson, M. L., Devlin, J. C., Dyson, P. L., Pinnock, M., Ye, H., Morris, R. J., and Waters, C. L.: Diurnal, seasonal, and geomagnetic activity variations in the occurrence of decametre-scale irregularities in the auroral and subauroral ionosphere, Proceedings of the Workshop on the Applications of Radio Science, Refereed Paper G9, Leura, New South Wales, 20-22 February, 2002a.

Parkinson, M. L., Dyson, P. L., Pinnock, M., Devlin, J. C., Hairston, M. R., Yizengaw, E., and Wilkinson, P. J.: Signatures of the midnight open-closed magnetic field-line boundary during balanced dayside and nightside reconnection, Ann. Geophysicae, 20, 1617-1630, 2002b.

Parkinson, M. L., Pinnock, M., Ye, H., Hairston, M. R., Devlin, 
J. C., Dyson, P. L., Morris, R. J., and Ponomarenko, P.: On the lifetime and extent of an auroral westward flow channel observed during a magnetospheric substorm, Ann. Geophysicae, 21, 893913, 2003.

Pinnock, M., Rodger, A. S., Dudeney, J. R., Baker, K. B., Newell, P. T., Greenwald, R. A., and Greenspan, M. E.: Observations of an enhanced convection channel in the cusp ionosphere, J. Geophys. Res., 98, 3767-3776, 1993.

Ponomarenko, P. V. and Waters, C. L.: The role of Pc1-2 waves in spectral broadening of SuperDARN echoes from high latitudes, Geophys. Res. Lett., 30, doi:10.1029/2002GL016333, 2003.

Ruohoniemi, J. M., Greenwald, R. A., Villain, J.-P., Baker, K. B., Newell, P. T., and Meng, C.-I.: Coherent HF radar backscatter from small-scale irregularities in the dusk sector of the subauroral ionosphere, J. Geophys. Res., 93, 12 871-12 882, 1988.

Ruohoniemi, J. M. and Greenwald, R. A.: Rates of scattering occurrence in routine HF radar observations during solar cycle maximum, Radio Sci., 32, 1051-1070, 1997.

Russell, C. T. and McPherron, R. L.: Semiannual variation of geomagnetic activity, J. Geophys. Res., 78, 92-108, 1973.

Shepherd, S. G. and Ruohoniemi, J. M.: Electrostatic potential patterns in the high latitude ionosphere constrained by SuperDARN measurements, J. Geophys. Res., 105, 23 005-23 014, 2000.

Starkov, G. V.: Statistical dependencies between the magnetic activity indices, Geomag. Aeronomy, 34, 101-103, 1994a.

Starkov, G. V.: Mathematical model of the auroral boundaries, Geomag. Aeronomy, 34, 331-336, 1994b.

Tsunoda, R. T.: High-latitude F-region irregularities: a review and synthesis, Rev. Geophys., 26 (4), 719-760, 1988.

Vickrey, J. F. and Kelley, M. C.: The effects of a conducting E layer on classical F-region cross-field plasma diffusion, J. Geophys. Res., 87, 4461-4468, 1982.

Villain, J. P., Caudal, G., and Hanuise, C.: A SAFARI-EISCAT comparison between the velocity of F-region small-scale irregularities and ion drift, J. Geophys. Res., 90, 8433-8444, 1985.

Villain, J. P., André, R., Pinnock, M., Greenwald, R. A., and Hanuise, C.: A statistical study of the Doppler spectral width of high latitude ionospheric F-region recorded with SuperDARN coherent HF radars, Ann. Geophysicae, 20, 1769-1781, 2002.

Yeoman, T. K., Lewis, R. V., Milan, S. E., and Watanabe, M.: An interhemispheric study of the ground magnetic and ionospheric electric fields during the substorm growth phase and expansion phase onset, J. Geophys. Res., 104, 14 867-14 877, 1999. 